\title{
Social Connections and Racial Wage Inequality*
}

\author{
Nicholas H. Tenev ${ }^{\dagger}$
}

May 2020

\begin{abstract}
How much of the wage gap between black workers and others in the US owes to differences in jobs found through social connections? Panel data from the NLSY79 are used to estimate a job search model in which individual human capital is distinguished from social capital by comparing the wages and frequency of jobs found directly with those of jobs found through friends. Jobs found through friends tend to pay more, but this premium is lower for black workers; the difference can account for $10 \%$ of the racial wage gap.
\end{abstract}

JEL codes: J71, J31, D85, Z13

\section{Introduction}

Social connections play an important role in finding work. ${ }^{1}$ But as not everyone has the same friends, some people may end up in higher-paying jobs than others, even if their qualifications are otherwise identical. This paper's contribution is to quantify the importance of this inequality in social capital to the oft-studied ${ }^{2}$ gap in labor market outcomes between black workers and others in the US. I estimate that $10 \%$ of the wage gap between these groups can be explained by differences in jobs found through friends, even after controlling for individual human capital.

*This paper was previously titled "Social Capital and Racial Inequality."

${ }^{\dagger}$ Office of the Comptroller of the Currency. The views expressed in this paper do not necessarily reflect the views of the Office of the Comptroller of the Currency, the U.S. Department of the Treasury, or any federal agency and do not establish supervisory policy, requirements, or expectations. This paper has benefitted enormously from discussions with Naoki Aizawa, Drew Anderson, Steven Durlauf, Chao Fu, Rasmus Lentz, Sean Lewis-Faupel, Corina Mommaerts, Chris Taber, Matt Wiswall, and also from comments from seminar participants at the University of Wisconsin-Madison.

${ }^{1}$ Granovetter (1973) found that roughly half of jobs are found through a social connection, and McDonald (2015) finds that jobs found through connections pay more. Other more recent work on the importance of referrals includes Ioannides and Datcher Loury (2004) and Schmutte (2016).

${ }^{2}$ See Altonji and Blank (1999) for a review. 
I develop a model similar to that of Burdett (1978), but with heterogeneous workers, wage growth with experience, and two types of offers. Workers receive job offers through direct search and also through friends. The chance of receiving an offer depends on its source, as well as worker characteristics including current employment status. A worker will accept an offer if it maximizes expected discounted utility from earnings. At the end of each period workers may lose their jobs; the chance of this happening depends on worker characteristics as well as how the job was found.

The parameters are estimated jointly via method of simulated moments on panel data from the NLSY79, which in certain years asks respondents whether their jobs were found through friends. This is the key to the identification strategy: the wages of jobs found directly provide a measure of individuals' human capital, allowing the relative wages of jobs found through friends to be used as a measure of social capital.

I find that the job offers black workers find through friends pay less than those of equally productive non-black workers. Montgomery $(1991$; 1992) showed how persistent inequality in wages and educational attainment can arise between two groups even if they have equal productive potential. Calvó-Armengol and Jackson (2004) explored a similar idea in an explicit network setting. The key to these papers is that if members of two groups are more likely to form in-group social connections (homophily), their labor market outcomes can follow different trajectories. Workers choose higher education or labor force participation because their friends are doing the same, and the payoffs to education or participation are higher if you have friends who can help you find a job (strategic complementarity). In a similar vein, Arrow and Borzekowski (2004) argue that plausible differences in network degree (number of connections) may account for black-white income disparity. I take these theoretical foundations to the data, and find that differences in jobs found through friends are indeed an important part of aggregate racial inequality in labor market outcomes. In addition, Section 7 sketches a model which adds endogenous network formation to a setup similar to Calvó-Armengol and Jackson (2004) to demonstrate that endogenous segregation and inequality in labor market outcomes can persist in equilibrium even when people can choose their friends.

This paper remains agnostic on exactly why friends are helpful in job search. The results are consistent with a model like that of Calvó-Armengol and Jackson (2004), in which friends are useful for alerting you that a vacancy exists. However, the main empirical results are also consistent with Simon and Warner (1992), in which referrals are valuable because they provide information to the hiring firm. ${ }^{3}$ As my data cannot distinguish between these mechanisms, firm behavior is not modeled: arrival rates and wage distributions are reduced-form specifications flexible enough

\footnotetext{
${ }^{3}$ Brown, Setren, and Topa (2015) find that panel data from a large US corporation support a model in which referrals are valuable because they convey information about workers' productivity. For example, jobs found through referrals tend to pay higher initial wages-a finding corroborated by this paper. See also Barr, Bojilov, and Munasinghe (2019).
} 
to qualitatively match a variety of possible explanations for why friends matter on the job market. The focus is instead on measuring how much the fruits of search through friends differ by race.

While much of the preceding literature on racial wage inequality has focused on skills disparities or employer discrimination, ${ }^{4}$ this paper demonstrates inequality in labor market outcomes that does not owe to either of these. ${ }^{5}$ These results are important because the implications of social capital disparities can be fundamentally different than those of skill disparities or discrimination. Audit or correspondence studies, for example, can detect discrimination by creating fictitious applicants who differ only in race (Kline and Walters, 2020), but may not be able to detect the disparate impact generated by referral hiring. And while affirmative action in hiring may not effectively address skills disparities, it may be able to balance out social capital inequality and provide disadvantaged groups with the same rewards to education enjoyed by groups with better social connections. Furthermore, it may increase the social capital of the disadvantaged group: the more minority workers have high-status jobs, the better the job-finding prospects of their friends. This can explain the finding of Miller (2017) that firms that increase their hiring of black workers to meet affirmative action standards required by government contracts tend to continue to do so even after they are no longer compelled to do so. Finally, while racial inequality is the focus of this paper, the importance of social capital may prove important for understanding inequality in other dimensions as well.

My results are broadly consistent with previous empirical work on inequality and jobs found through social connections. Schmutte (2015) uses geographic variation to show that social interactions can explain why some workers get higher paying jobs. Holzer (1987) finds that differences in job finding rates can account for most of the racial difference in unemployment outcomes for youths, Green, Tigges, and Diaz (1999) find that jobs found through friends pay less for black workers in certain cities, and Petersen, Saporta, and Seidel (2000) focus on advancement within a particular firm. This paper makes two main contributions relative to this previous empirical work. The first is scope-I use nationally representative panel data and consider both unemployment and wages of early- and mid-career workers. My work builds on that of others using the NLSY79 (e.g. Parks-Yancy (2006) and Mouw (2002)) by using more waves of the study and a labor search model, to address the concerns of Mouw (2002) that fixed-effects regression results are inconclusive. ${ }^{6}$ Second, I allow the wage premium of jobs found through friends to vary with human capital, to avoid misinterpreting group differences in human capital as differences in social capital (see

\footnotetext{
${ }^{4}$ For example, Carneiro, Heckman, and Masterov (2005) study skills disparities, Coate and Loury (1993) examine statistical discrimination and affirmative action, and Fang and Moro (2011) and Guryan and Charles (2013) review other work in this vein.

${ }^{5}$ Rather, firms can be thought of as discriminating on the basis of social connections, which differ by race. This paper's mechanism thus better exemplifies what Small and Pager (2020) call "institutional discrimination."

${ }^{6}$ See also McDonald (2015), who studies jobs found through connections with the same dataset and a panel approach but does not focus on racial inequality.
} 
Section 4.2 for further discussion).

Other work in this area provides complementary explanations for persistent inequality. Becker and Tomes (1979) and Loury (1981) show that inequality can persist if lower-income parents invest less in their children's education. Durlauf (1996) shows that gaps between neighborhoods can persist where education is a local public good. This paper establishes the importance of network job-finding alongside these other mechanisms as a key driver of racial inequality, isolating differences in job-finding which owe entirely to differences in social connections.

Section 2 motivates the research, reviewing stylized facts about race, labor market outcomes, and social connections. Section 3 develops the labor market model. Section 4 describes the data used and, for those short on time, performs preliminary analysis that roughly encapsulates the main result in a single fixed-effects regression. Section 5 explains the estimation and identification strategy, and Section 6 presents the main results. Section 7 sketches out an underlying mechanism of network formation, human capital investment, and labor market search with referrals to show that the main results can persist in equilibrium even when friends are chosen.

\section{Stylized facts}

Two stylized facts about the US labor market are essential to this paper. First, labor market outcomes differ by race. Figures 1 and 2 show (using Bureau of Labor Statistics data) that black workers earn less and are more likely to be looking for work. Racial gaps in earnings and unemployment also exist across education levels. And across education levels, employed black workers report fewer job offers, as shown by Table $1 .^{7}$

Table 1: Job offers by education and race

\# other offers when found job

\begin{tabular}{|c|c|c|}
\hline Years of school & Non-black & Black \\
\hline \hline$<12$ & 0.31 & 0.23 \\
\hline 12 & 0.37 & 0.29 \\
\hline $13-15$ & 0.51 & 0.40 \\
\hline $16+$ & 0.74 & 0.70 \\
\hline
\end{tabular}

Source: NLSY79

Second, the socioeconomic advantage of social connections is also unequally distributed by race. This is in part a consequence of racial homophily - the tendency of people to have friends of

\footnotetext{
${ }^{7}$ This table uses data from the NLSY79, described in Section 4.1. Wolpin (1992) finds that young black workers who did not go to college receive more job offers than average; these figures provide a broader view. McDonald (2011) finds that workers with more white male connections receive more job leads.
} 
Figure 1: Racial inequality in earnings

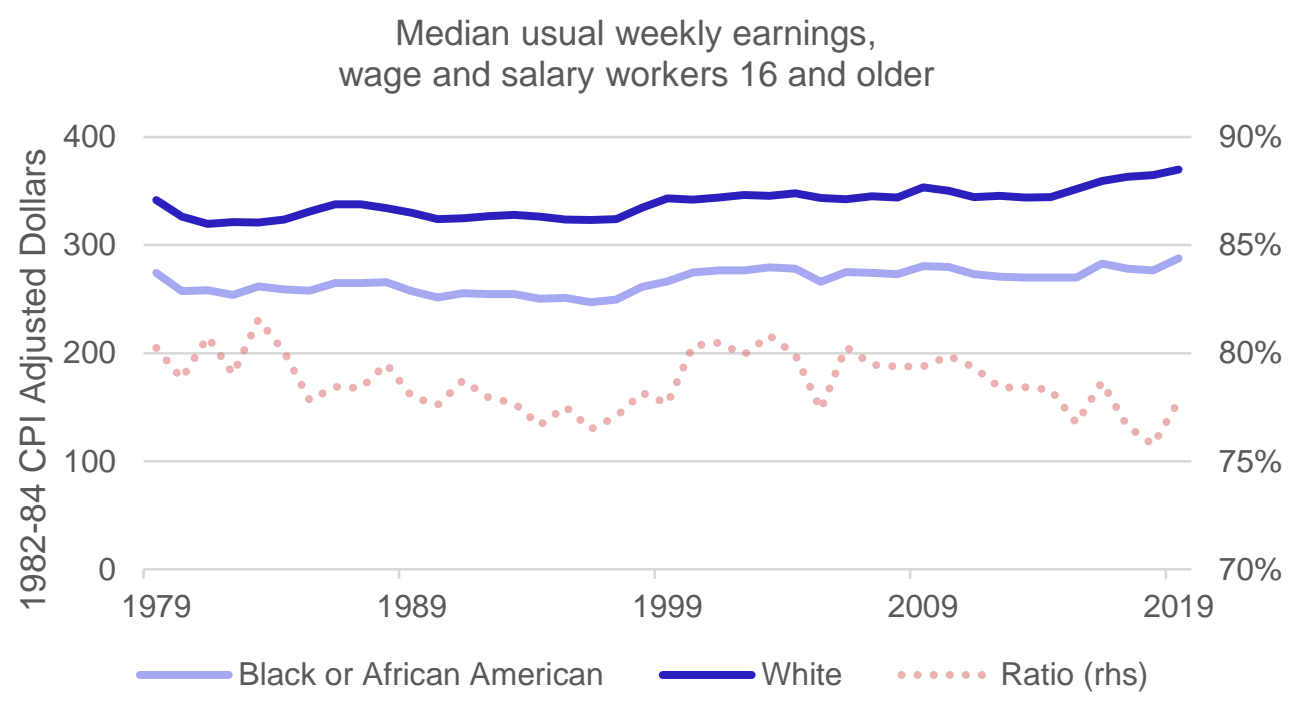

Source: Bureau of Labor Statistics

the same race. Figure 3 shows that in Add Health data, the friends of black workers are more likely to be out of work, especially at lower levels of educational attainment. The friends of black workers at all levels of educational attainment also tend to have less formal education: for example, $21 \%$ of the friends of black respondents with exactly 12 years of education did not finish high school, compared with $14 \%$ for the friends of non-black respondents. ${ }^{8,9}$

Taken together, these facts suggest that non-black workers may have an advantage in finding high-paying work through friends. To fix terminology, "social capital" in this paper refers to any factors which affect jobs found through friends but not those found directly.

\footnotetext{
${ }^{8}$ The Add Health survey began with a nationally representative sample of students in grades 7-12 in the 19941995 school year. The data presented here are from Wave III, conducted in 2001-02, when respondents were aged 18-26. Crucially, some Wave III survey respondents had an opportunity to identify other respondents (from a randomly generated list of ten names) as friends, yielding a sample of 3,572 respondents for whom we have data on both the respondent and up to ten friends.

${ }^{9}$ This research uses data from Add Health, a program project directed by Kathleen Mullan Harris and designed by J. Richard Udry, Peter S. Bearman, and Kathleen Mullan Harris at the University of North Carolina at Chapel Hill, and funded by grant P01-HD31921 from the Eunice Kennedy Shriver National Institute of Child Health and Human Development, with cooperative funding from 23 other federal agencies and foundations. Information on how to obtain the Add Health data files is available on the Add Health website (http://www.cpc.unc.edu/addhealth). No direct support was received from grant P01-HD31921 for this analysis.
} 
Figure 2: Racial inequality in unemployment

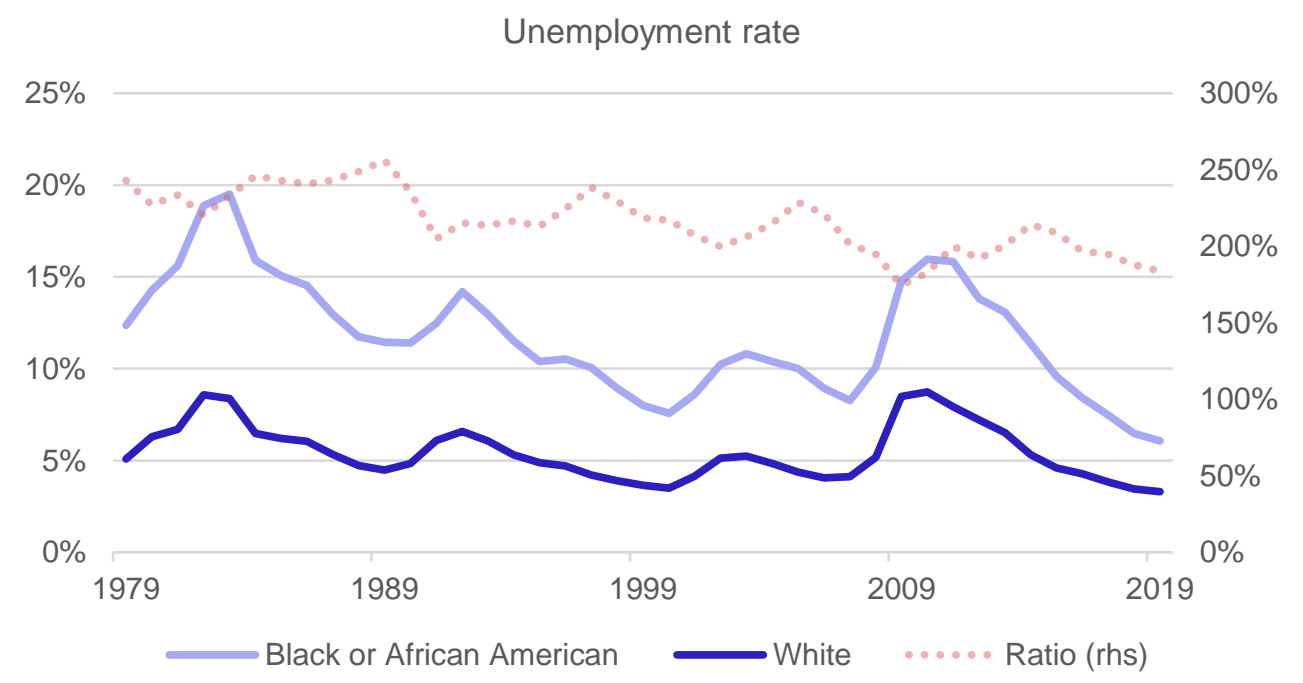

Source: Bureau of Labor Statistics

\section{Model}

Consider a group $I$ of $n$ workers who have completed their schooling and seek to maximize expected discounted utility from earnings. Time progresses in discrete periods $t=1,2,3, \ldots$, each of which is 2 weeks long. ${ }^{10}$ Each period, a worker may receive up to one job offer. Job offers come in two flavors: those found directly and those found through friends. The chance of receiving a direct offer is $\lambda_{i t}^{d}$ and the chance of receiving an offer through friends is $\lambda_{i t}^{f}$ (parameterized below in Equations 5 and 6). A worker who receives an offer in period $t$ can either accept it or reject it and maintain the status quo-his current job (if employed) or unemployment (if not). This is the only choice made by workers in the model. At the end of the period, an employed worker $i$ loses his job with chance $\delta_{i t}$.

The $\log$ wage that worker $i$ receives at time $t$ from job $j$ if the job was found directly is:

$$
w_{i j(t)}^{d}=\eta_{i}+h_{i t}+\epsilon_{i j(t)}^{d}
$$

The log wage of a job found through friends is:

$$
w_{i j(t)}^{f}=\beta_{\text {hcap }} \eta_{i}+\beta_{\exp } h_{i t}+\beta_{0}+\beta_{s} s_{r(i)}+\epsilon_{i j(t)}^{f} .
$$

\footnotetext{
${ }^{10}$ The length of each period was chosen to be as short as possible while still computationally feasible.
} 
Figure 3: Employment rate of friends

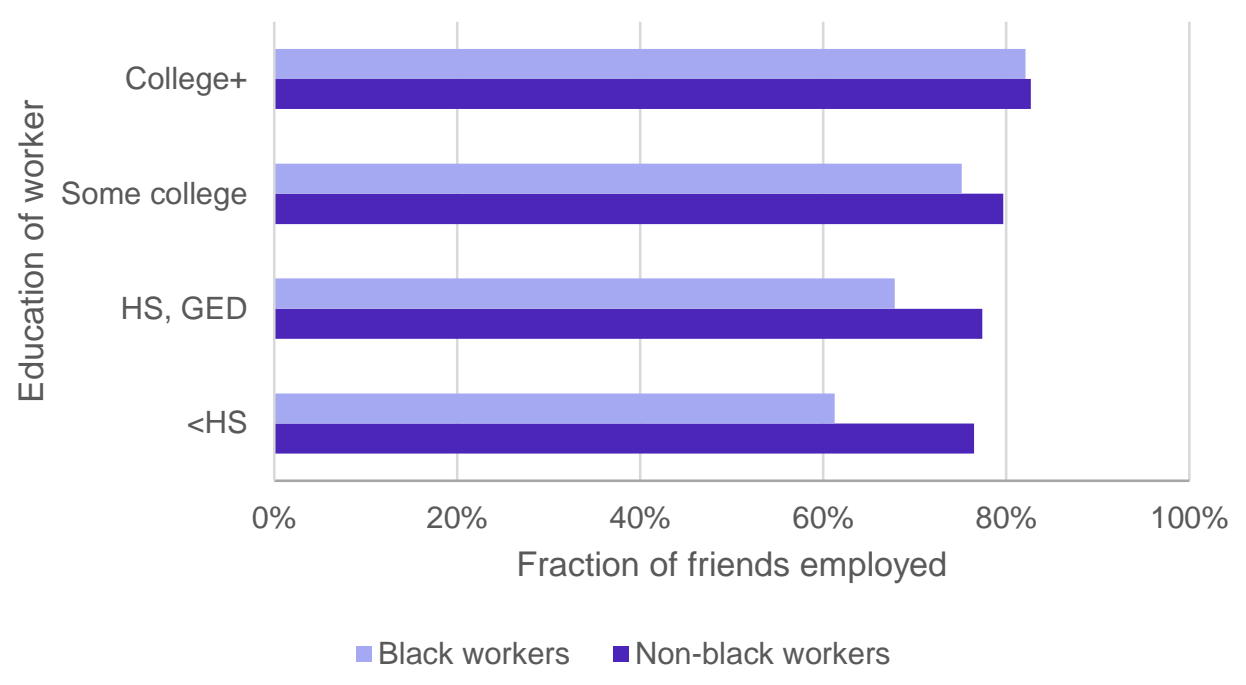

Source: Add Health

Each worker is endowed with initial marketable human capital $\eta_{i}$, which can be thought of as summarizing characteristics relevant to productivity such as education and ability. While $\eta_{i}$ will be referred to as "human capital" throughout the paper, it is best thought of as $i$ 's earning power. For example, $\eta_{i}$ will not be $i$ 's true productive capacity if discrimination means that $i$ is paid less than her true productive capacity. In this case $\eta_{i}$ can be thought of how much $i$ can expect to be paid under the current discriminatory regime. This is discussed further in Section 5.3 and Appendix C.

Initial human capital is distributed normally with parameters that may differ by race $\left(r_{i} \in\{0,1\}\right.$ denotes whether $i$ reports being black), reflecting differences in early childhood circumstances, educational attainment, or other factors that influence human capital: ${ }^{11}$

$$
\eta_{i} \sim N\left(\mu_{r(i)}, \sigma_{r(i)}^{2}\right)
$$

Worker $i$ 's wage at job $j$ depends on acquired human capital $h_{i t}$, which in turn grows mechanically with work experience, $x_{i t}$ :

$$
h_{i t}=\max \left(\alpha_{1} x_{i t}+\alpha_{2} x_{i t}^{2}, h_{i t-1}, h_{t-2}, \ldots\right) .
$$

\footnotetext{
${ }^{11}$ For example, Aizer and Currie (2019) find that black children face higher exposure to lead, effecting higher rates of school suspension and juvenile detention; Hamilton and Darity (2017) discuss the black wealth gap and education; Thompson (2018) studies the effect of the civil rights movement on parenting practices; Sacerdote (2011) reviews the literature on peer effects and student performance.
} 
This acquired human capital is parameterized as a quadratic, with the stipulation that its growth can fall to zero but cannot turn negative (this technical assumption is made to avoid the unnatural scenario of a worker preferring unemployment to avoid losing human capital). The law of motion for work experience $x_{i t}$ is simply that it increases by one every period that the worker is employed.

The shock $\epsilon_{i j}^{d}$ represents how productive worker $i$ is at firm $j$, and is drawn from a normal distribution with mean normalized to zero and standard deviation $\sigma^{d}$. For jobs found through friends, the analogous match quality between worker and firm is $\beta_{0}+\beta_{s} s_{r(i)}+\epsilon_{i j(t)}^{f}$, where $\epsilon_{i j(t)}^{f}$ is normally distributed with mean zero and standard deviation $\sigma^{f}$. This allows for the possibility that jobs found through friends provide better or worse productivity matches $\left(\beta_{0}\right)$, and that this difference depends on race $\left(\beta_{s} s_{r(i)}\right)$.

Each worker is endowed with social capital $s_{r(i)}$, which represents the average difference in social capital between black and non-black workers. Having no natural units, it is equal to one for black workers and zero otherwise. This is of course a simplification-the implications of heterogeneity in social capital within racial groups are discussed in Section 5.3 and Appendix C. Section 2 highlighted several group-level differences in social connections that we might expect to influence job search; the goal of this paper is to determine the degree to which such differences translate into aggregate differences in labor market outcomes. In the model, social capital affects both the arrival of new offers found through friends and the wages they promise, but not offers found directly.

A worker's wage can grow over the life cycle by remaining in the same job and gaining experience, or by moving to a job with a better productivity match quality $\epsilon_{i j}$. But a worker's match quality at a given job $j$ does not change over time.

When workers are unemployed, they receive unemployment insurance equal to $40 \%$ of the most recent wage up to a maximum of \$130/week (in 1979 dollars), roughly corresponding to typical US unemployment insurance laws. If a worker has never worked, as is the case when entering the labor market for the first time, the worker's initial human capital $\eta_{i}$ is used in place of the most recent wage.

The chance of receiving an offer directly $\left(\lambda_{i t}^{d}\right)$ and the chance of receiving an offer through friends $\left(\lambda_{i t}^{f}\right)$ are parameterized as follows. First, define the following intermediate variables:

$$
\begin{gathered}
\tilde{\lambda}_{i t}^{d}=\Lambda_{0}^{d}+\Lambda_{\text {race }}^{d} r_{i}+\Lambda_{\text {hcap }}^{d} \eta_{i}+\Lambda_{\text {exp }}^{d} h_{i t}+\Lambda_{u}^{d} u_{i t} \\
\tilde{\lambda}_{i t}^{f}=\Lambda_{0}^{f}+\Lambda_{\text {race }}^{d} r_{i}+\Lambda_{\text {hcap }}^{f} \eta_{i}+\Lambda_{\text {exp }}^{f} h_{i t}+\Lambda_{s}^{f} s_{r(i)}+\Lambda_{u}^{f} u_{i t} .
\end{gathered}
$$

Since these specifications are linear, $\tilde{\lambda}_{i t}^{d}$ and $\tilde{\lambda}_{i t}^{f}$ may not be bounded to the unit interval. I 
therefore use the logistic function $\mathcal{L}(x)=\frac{1}{1+e^{-x}}$ to parameterize the probabilities of receiving offers directly and through friends as

$$
\begin{aligned}
& \lambda_{i t}^{d}=\frac{\mathcal{L}\left(\tilde{\lambda}_{i t}^{d}\right)}{\mathcal{L}\left(\tilde{\lambda}_{i t}^{d}\right)+\mathcal{L}\left(\tilde{\lambda}_{i t}^{f}\right)} \mathcal{L}\left(\tilde{\lambda}_{i t}^{d}+\tilde{\lambda}_{i t}^{f}\right) \\
& \lambda_{i t}^{f}=\frac{\mathcal{L}\left(\tilde{\lambda}_{i t}^{f}\right)}{\mathcal{L}\left(\tilde{\lambda}_{i t}^{d}\right)+\mathcal{L}\left(\tilde{\lambda}_{i t}^{f}\right)} \mathcal{L}\left(\tilde{\lambda}_{i t}^{d}+\tilde{\lambda}_{i t}^{f}\right) .
\end{aligned}
$$

This ensures that each probability lies within the unit interval, and that their sum does as well (recall that only one offer may arrive each period, so these are the probabilities of disjoint events).

The arrival of each type of offer thus depends on $i$ 's race $r_{i}$, initial human capital $\eta_{i}$, accumulated human capital $h_{i t}$, an indicator $u_{i t}$ of whether $i$ is unemployed in period $t$, and a constant. The arrival rate of jobs found through friends depends on all of these and also on social capital $s_{r(i)}$. As the arrival of offers through friends (Equation 6) also includes the $\Lambda_{\text {race }}^{d} r_{i}$ term that determines the arrival of direct offers (Equation 5), the social capital coefficient $\Lambda_{s}^{f}$ will capture differences in arrival of offers through friends not explained by differences in the direct offer arrival rate- this is analogous to the $\beta_{s} s_{r(i)}$ term in the wage equation 2.

Finally, at the end of each period an employed worker's job is destroyed with chance $\delta_{i t}$ :

$$
\delta_{i t}=\mathcal{L}\left(\Delta_{0}+\Delta_{\text {race }} r_{i}+\Delta_{\text {hcap }} \eta_{i}+\Delta_{\text {exp }} h_{i t}+\Delta_{f} f_{i j(t)}\right)
$$

The logistic function $\mathcal{L}$ is again used to bound this probability inside the unit interval. The chance of losing one's job depends on $f_{i j(t)}$, an indicator of whether $i$ 's job $j$ at time $t$ was found through friends. Jobs found through friends may be a better match for a worker's skills, or it may be more enjoyable to work with friends. More cynically, it may be harder to fire someone who is a friend or relative of the boss.

It is theoretically possible in this model that an employed worker might want to quit to unemployment. Since the chance of finding a new job changes with age, the relative value of unemployment may have increased since the worker accepted her current job offer. However, at the estimated parameter values this is never the case, and thus this possibility is ignored: employed workers never choose to quit to unemployment.

What offers will a worker accept? Worker $i$ 's value of employment at job $j$ with match quality $\epsilon_{i j}$ and experience $x_{i t}$ at time $t$ can be written as follows. Note that the value also depends on race 
$r_{i}$, social capital $s_{i}$, and initial human capital $\eta_{i}$, but as they are time-invariant these arguments are suppressed and replaced with a dot $(\cdot)$.

$$
\begin{gathered}
V\left(\epsilon_{i j(t)}, f_{i j(t)}, a_{i t}, x_{i t}\right)=w_{i j(t)}+\rho\left\{\delta_{i t} U\left(w_{i j(t)}, a_{i t+1}, x_{i t}, \cdot\right)+\left(1-\delta_{i t}\right)\left[V\left(\epsilon_{i j(t)}, f_{i j(t)}, a_{i t+1}, x_{i t}+1, \cdot\right)\right.\right. \\
\left(\left(1-\lambda_{i t}^{d}-\lambda_{i t}^{f}\right)+\lambda_{i t}^{d} \Phi^{d}\left(\underline{\epsilon}^{e d}\left(\epsilon_{i j(t)}, f_{i j(t)}, a_{i t}, x_{i t^{*}}\right)\right)+\lambda_{i t}^{f} \Phi^{f}\left(\underline{\epsilon}^{e f}\left(\epsilon_{i j(t)}, f_{i j(t)}, a_{i t}, x_{i t}, \cdot\right)\right)\right) \\
+\lambda_{i t}^{d} \int_{\underline{\epsilon}^{e d}\left(\epsilon_{i j(t)}, f_{i j(t)}, a_{i t}, x_{i t}, \cdot\right)}^{\infty} V\left(\epsilon_{i j^{\prime}}, 0, a_{i t+1}, x_{i t}+1, \cdot\right) d \phi^{d}\left(\epsilon_{i j^{\prime}}\right) \\
\left.\left.+\lambda_{i t}^{f} \int_{\underline{\epsilon}^{e f}\left(\epsilon_{i j(t)}, f_{i j(t)}, a_{i t}, x_{i t} \cdot\right)}^{\infty} V\left(\epsilon_{i j^{\prime}}, 1, a_{i t+1}, x_{i t}+1, \cdot\right) d \phi^{f}\left(\epsilon_{i j^{\prime}}\right)\right]\right\}
\end{gathered}
$$

First, the worker receives the wage flow, $w_{i j(t)}$. With chance $\delta_{i t}$ (given by equation 9), worker $i$ 's job is lost and starts the next period (discounted by $\rho$ ) with a value of unemployment $U$ that depends on the wage of the job lost as well as the worker's new age $a_{i t+1}$; in this case the worker's experience remains at $x_{i t}$. With chance $1-\delta_{i t}$, the job is not lost. The second line contains the chance of remaining in the same job-this can happen either by receiving no offers (chance $\left.\left(1-\lambda_{i t}^{d}-\lambda_{i t}^{f}\right)\right)$ or by receiving a job offer at a firm that is below the worker's reservation match quality for offers received in employment $\left(\underline{\epsilon}^{e f}\right.$ for jobs found through friends and $\underline{\epsilon}^{\text {ed }}$ for jobs found directly). The reservation match quality depends on the current match quality, and worker's age, and experience. It also depends on on how the new and old offers were found since this can affect how likely the job is to be lost. So a worker may, for example, be willing to accept a slightly lower wage for a job found through friends if it is likely to last longer. $\Phi^{d}$ and $\Phi^{f}$ are normal cumulative densities with mean zero and standard deviations $\sigma^{d}$ and $\sigma^{f}$, reflecting the distribution of match quality.

The third line contains the chance and value that a direct job offer is received and the match quality $\epsilon_{i j^{\prime}}$ of the new job $j^{\prime}$ is above the reservation match quality. The fourth line contains the chance and value that an offer is received through friends and it is of acceptable match quality. Here $\phi^{d}$ and $\phi^{d}$ are normal densities of mean zero and standard deviations $\sigma^{d}$ and $\sigma^{f}$, again reflecting the distribution of match quality.

The value of unemployment depends on the most recent wage $w_{i j(t)}$ at time $t$ as well as age and experience (when a worker is unemployed, define for convenience $w_{i j(t)}$ as their most recent 
wage).

$$
\begin{aligned}
U\left(w_{i j(t)}, a_{i t}, x_{i t}, \cdot\right) & =\max \left\{w_{i j(t)}+\log (0.4), \log (\$ 130 \times 2)\right\}+\rho[ \\
\left(\left(1-\lambda_{i t}^{d}-\lambda_{i t}^{f}\right)+\right. & \left.\lambda_{i t}^{d} \Phi^{d}\left(\underline{\epsilon}^{u d}\left(w_{i j(t)}, a_{i t}, \cdot\right)\right)+\lambda_{i t}^{f} \Phi^{f}\left(\underline{\epsilon}^{u f}\left(w_{i j(t)}, a_{i t}, \cdot\right)\right)\right) U\left(w_{i j(t)}, a_{i t+1}, x_{i t}, \cdot\right) \\
& +\lambda_{i t}^{d} \int_{\underline{\epsilon}^{u d}\left(\epsilon_{i j(t)}, f_{i j(t)}, a_{i t}, \cdot\right)}^{\infty} V\left(\epsilon_{i j^{\prime}}, 0, a_{i t+1}, x_{i t}, \cdot\right) d \phi^{d}\left(\epsilon_{i j^{\prime}}\right) \\
& \left.+\lambda_{i t}^{f} \int_{\underline{\epsilon}^{u f}\left(w_{i j(t)}, f_{i j(t)}, a_{i t}, \cdot\right)}^{\infty} V\left(\epsilon_{i j^{\prime}}, 1, a_{i t+1}, x_{i t}, \cdot\right) d \phi^{f}\left(\epsilon_{i j^{\prime}}\right)\right]
\end{aligned}
$$

The value of unemployment has four parts. First is unemployment insurance, which depends on the most recent wage and is described above. The second line contains the chance and value of remaining unemployed in the following period, which occurs if either no offer arrives or if one does but it is below the reservation match quality. Note that since the flow value of unemployment insurance depends on a worker's most recent wage but is invariant to how that job was found, the reservation match qualities in unemployment $\underline{\epsilon}^{u f}$ and $\underline{\epsilon}^{u d}$ likewise depend on the most recent wage but not its provenance. They still depend on the provenance of the new offer, however, as again this affects the chance of the job being lost. And as in Burdett (1978), a worker may prefer to remain in unemployment than take a low offer, given that the search rate is higher in unemployment. The third line contains the chance and value of an acceptable offer through direct search, and the fourth line contains the chance and value of an acceptable offer arriving through friends. In all cases the worker's experience $x_{i t}$ does not grow, as they are unemployed this period.

In this model there are three distinct ways in which friends can help you on the labor market:

1. More offers

\section{Higher-paying offers}

3. Jobs less likely to be lost ${ }^{12}$

The focus of this paper is whether or not social capital differs by race in a way that affects jobs found through friends through these three channels.

\footnotetext{
${ }^{12}$ Datcher Loury (2006) and Brown, Setren, and Topa (2015) have found that jobs found through social connections last longer.
} 


\section{Data and preliminary analysis}

\subsection{Data}

The model is estimated using the NLSY79, a longitudinal study of a sample of 12,686 people in the US who were nationally representative when first surveyed in 1979, at ages 14-22.13 In years 1982, 1994, 1996, 1998, and 2000, respondents who reported working were asked whether or not they found their job through asking friends or relatives. Specifically, those who reported looking for work when offered their current job are asked "Which of the methods on this card led to your being offered your job with [Name of employer]?" I identify this as a job found through friends/relatives if they marked "Contacted friends or relatives." 14

For these jobs (up to five for each year), respondents also reported their wages, occupation, and whether they were working when they found the job. Another important feature of the data is a cumulative work experience over the entire sample (not just the years in which job provenance is asked about). All dollar values are deflated using the CPI-U-RS published by the Bureau of Labor Statistics. ${ }^{15}$ Educational attainment is also reported, and the sample is restricted to include only those observations for which respondents had reached their highest level of education. The data also include sex, race, age, and employment and marital status. This paper focuses on differences in outcomes between black workers and others.

\subsection{Preliminary analysis}

Before estimating the full model, the main result can be roughly encapsulated in a single fixedeffects regression. Log weekly earnings are regressed on whether the job was found through friends, the interaction of this variable with race, and a variety of other controls including individual fixed effects. Selected coefficients are reported in Table 2.

\footnotetext{
${ }^{13}$ The NLSY79 survey (Bureau of Labor Statistics, US Department of Labor, 2019) is sponsored and directed by the U.S. Bureau of Labor Statistics and managed by the Center for Human Resource Research (CHRR) at The Ohio State University. Interviews are conducted by the National Opinion Research Center (NORC) at the University of Chicago.

${ }^{14}$ Other possible search methods include checking with a state employment agency, checking with a private employment agency, contacting an employer directly, placing or answering an ad, and looking in a newspaper; respondents are instructed to mark all that apply.

${ }^{15}$ McHenry and McInerney (2014) argue that accounting for local cost of living and years of education is important in measuring the relative wages of black women. My paper includes individual fixed effects to account for education, but to the extent that local cost of living is higher for some workers, the wage gap as measured here may understate the gap in purchasing power.
} 
Table 2: Wage premium of jobs found through friends

Fixed effects regression of log weekly earnings

\begin{tabular}{lcc}
\hline Variable & Coefficient & Std. Err. \\
\hline Job found through friends & 0.194 & 0.015 \\
Black $\times($ job found through friends $)$ & -0.080 & 0.035 \\
Experience & 0.139 & 0.011 \\
Experience ${ }^{2}$ & -0.003 & $3.50 \mathrm{E}-4$ \\
Married & $-5.10 \mathrm{E}-4$ & 0.025 \\
Married $\times$ male & 0.132 & 0.034 \\
\hline \# obs. & \multicolumn{2}{c}{24,433} \\
\# individuals & \multicolumn{2}{c}{8,510} \\
\hline orted coefficients include individual fixed effects, an indicator for urban location, year dummies, and a constant.
\end{tabular}

Jobs found through friends tend to pay more, but the premium is lower for black workers. This is the main result of the paper-inequality in social capital seems to be driving part of the racial wage gap, even after controlling for individual human capital.

Could this result still owe to differences in human capital, rather than social capital? Consider the following model.

$$
\begin{gathered}
w_{i j(t)}^{d}=\eta_{i}+\beta_{X}^{d} X_{i t}+\epsilon_{i j(t)}^{d} \\
w_{i j(t)}^{f}=\beta_{\mathrm{hcap}} \eta_{i}+\beta_{X}^{f} X_{i t}+\beta_{s} s_{i}+\epsilon_{i j(t)}^{f} .
\end{gathered}
$$

If the wages of jobs found through friends depend differently on human capital $\left(\beta_{\text {hcap }} \neq 1\right)$, then a group difference in average human capital could show up in Table 2 even if $\beta_{s}=0$. For example, if jobs found through friends yield higher wages only for workers with lots of human capital ( $\beta_{\text {hcap }}>$ 1 ), then a group with less human capital will have a lower average premium for jobs found through friends.

To address this concern, I first run a fixed-effects regression of the log wages of jobs found directly (Equation 10) to obtain estimates of individual human capital $\hat{\eta}_{i}$. These estimates are then used to estimate Equation 11. The results are given in the first column of Table 3. Note that the estimated coefficient for black workers is essentially the same as in Table 2. 
Table 3: Wage premium of jobs found through friends

Regression of log weekly earnings of jobs found through friends

\begin{tabular}{lcc|cc} 
& \multicolumn{2}{c}{$(1)$ Naïve } & \multicolumn{2}{c}{$(2)$ Corrected } \\
\hline Variable & Coefficient & Std. Err. & Coefficient & Std. Err. \\
\hline Estimated fixed effect from Eq. 10 & 0.325 & 0.018 & 0.446 & 0.027 \\
Black & -0.079 & 0.020 & -0.071 & 0.020 \\
Experience & 0.114 & 0.010 & 0.122 & 0.010 \\
Experience ${ }^{2}$ & -0.003 & 0.000 & -0.003 & 0.000 \\
Married & -0.093 & 0.026 & -0.076 & 0.026 \\
Married $\times$ male & 0.379 & 0.029 & 0.338 & 0.030 \\
\hline \# obs. & \multicolumn{4}{c}{4,658} \\
\hline \multicolumn{2}{c}{ Note: Unreported coefficients include an indicator for urban location, year dummies, and a constant. }
\end{tabular}

The fixed effect estimates $\hat{\eta}_{i}$ are fairly noisy, as there are typically only a few wage observations per individual. This will bias lower the estimated coefficient on $\eta$, and may artificially inflate the magnitude of our coefficient of interest. Fortunately, we have a good sense how noisy $\hat{\eta}_{i}$ is, since we often observe multiple wages per individual at jobs found directly. Appendix B details a procedure for correcting this measurement error, and the second column of Table 3 gives the corrected results: the coefficient of interest is modestly attenuated.

To determine the extent to which racial wage inequality is explained by social capital, I predict log weekly earnings for jobs found through friends using the corrected coefficient estimates from Table 3, but setting the race dummy equal to zero for all individuals. The predicted weekly earnings (converted to 2016 dollars for convenience) are given by Table 4.

Table 4: Weekly earnings predicted by linear regression (2016 \$)

\begin{tabular}{cccc} 
& Black & Non-black & Gap \\
\hline \hline Actual & 363 & 419 & 56 \\
Predicted & 363 & 419 & 56 \\
Counterfactual & 368 & 419 & 50 \\
\hline
\end{tabular}

This suggests that inequality in social capital can explain $10 \%$ of the racial gap in log weekly earnings.

Could it be the case that there is a racial difference in human capital that leads non-black workers to pursue careers in occupations in which social capital matters more? The network wage premium does vary by occupation (see Table 11 in Appendix A), but the estimated racial difference in network wage premium is actually slightly larger if controls for each worker's occupation are 
included. So the result does not seem to be driven by a difference in the importance of social capital in different occupations.

It may be the case that when a firm hires a worker through a referral, it is more certain that the worker has high productivity. If this were driving the results, then the racial difference in the network wage premium should shrink with tenure, a firms learn more about the productivity of their workers and the information gap between referrals and direct hires closes. However, the evidence does not support this: the estimated racial difference in network wage premium is slightly larger if the sample is restricted to only include jobs which workers have held for at least a year. So the main result holds even for those observations for which firms have had ample time to learn about workers' productivity.

How does this fit in with previous findings that most of the wage gap can be accounted for by premarket factors? O'Neill (1990) and Neal and Johnson (1996) find that in a regression of $\log$ wages on AFQT score and race, variation in the former is able to account for nearly all the variation in the outcome. This is interpreted as evidence that premarket factors such as human capital formation are responsible for the racial wage gap, rather than bias in hiring against black workers of equal productivity. ${ }^{16}$ Table 12 in the Appendix shows the results of a similar exercise carried out separately for jobs found through friends and for jobs found directly. In jobs found directly, differences in AFQT can largely account (in a statistical sense) for racial inequality in earnings, as in previous work. But for jobs found through friends, the coefficient on race is large (and statistically significant), suggesting that there is racial variation in jobs found through friends that requires another explanation.

Given this result, estimating the model can fill in some important details. First, the racial discrepancy in the network wage premium could owe to better offers or simply more offers. Distinguishing these effects requires estimating the full model. Second, the exercise above is unable to address important issues of selection. In particular, changing the offers black workers find through friends could cause some workers to choose a different offer, or pull some workers out of unemployment - eventualities not addressed by the reduced-form counterfactual. Finally, the secondary effect of increased experience may also be important, and is captured in the model.

\footnotetext{
${ }^{16}$ To the extent that social connections are formed before entering the labor market they are a premarket factor, and variation in AFQT score may reflect both individual productivity as well as something about one's social connections, making it an imperfect way to separate an individual's characteristics from those of her social connections.
} 


\section{Estimation}

\subsection{Identification}

A key feature of the data is that for each individual, multiple jobs are observed over time, some of which are found directly and some of which are found through friends. This allows individual human capital, which affects both types of offers, to be distinguished from the individual's social capital, which only affects the latter.

The 27 parameters are estimated jointly via method of simulated moments. Given a set of parameters, I first determine the reservation match quality in each state. To do so, I solve backwards assuming log utility, exogenous retirement at age 65, and a time discount factor $\rho$ of $95 \%$ (per year). The continuous variables (initial human capital and match quality) as well as experience are each approximated by a 12-point grid. Finer grids were also tried, with no appreciable effect on results.

Next, I simulate each worker's wage path from the first quarter following the end of schooling through the year 2000, when the data end. When a worker's simulated human capital or the match quality of a simulated offer lie between grid points, linear interpolation is used to determine the reservation match quality. From these complete wage paths, I censor the simulated observations to include only those worker-period observations included in the NLSY79 data set.

The censored simulated data can then be compared to the actual data through the lens of certain judiciously chosen moments and regression coefficients, which are described below and summarized in Table 5. To avoid redundancy, not every coefficient from a given regression is targeted in estimation; these coefficients are marked in Table 5 with a dagger $(\dagger)$.

First, log wages are regressed on experience $x_{i t}$, its square, an indicator $f_{i t}$ of whether the job was found through friends, and the interaction of this indicator with race $r_{i}$ and experience and its square. This regression also includes individual dummy variables $\left\{d_{i}\right\}$; the estimated coefficients on these indicator variables (fixed effects) are denoted $\hat{\eta}_{i}$. The coefficients not including the fixed effects help identify the parameters $\left\{\alpha_{1}, \alpha_{2}\right\}$ from Equation 1, which determine the growth of human capital with experience and its square. They also help identify the three parameters $\left\{\beta_{0}, \beta_{\exp }, \beta_{s}\right\}$ in Equation 2, which determine the distribution of wages of jobs found through friends. The final parameter in this equation, $\beta_{\text {hcap }}$, is pinned down by the coefficient on the estimated fixed effect $\hat{\eta}_{i}$ in a separate regression of log wages on jobs found through friends that also includes a constant, race $r_{i}$, and experience $x_{i t}$.

A regression of the estimated fixed effect $\hat{\eta}_{i}$ on a constant, race, experience, and its square identifies the means of the initial human capital distribution $\left\{\mu_{r(i)}\right\}$ from Equation 3 and also helps identify the dependence of human capital on experience. The standard deviations of the fixed effect for non-black and black workers identify the dispersion of initial human capital $\left\{\sigma_{r(i)}\right\}$, and the standard deviations of wages less the fixed effect $\left(w_{i t}-\hat{\eta}_{i}\right)$ for jobs found directly and through 
Table 5: Targeted statistics

Included independent variables

\begin{tabular}{ll|llllllllll} 
& Dependent variable & 1 & $r_{i}$ & $x_{i t}$ & $x_{i t}{ }^{2}$ & $f_{i t}$ & $f_{i t} \cdot r_{i}$ & $f_{i t} \cdot x_{i t}$ & $f_{i t} \cdot x_{i t}^{2}$ & $\left\{d_{i}\right\}$ & $\hat{\eta}_{i}$ \\
\hline \hline (1) & Log wage $w_{i t}$ & & & $\checkmark$ & $\checkmark$ & $\checkmark$ & $\checkmark$ & $\checkmark$ & $\checkmark$ & $\checkmark^{\dagger}$ & \\
(2) & $w_{i t}$, job through friends & $\checkmark$ & $\checkmark^{\dagger}$ & $\checkmark^{\dagger}$ & & & & & & & $\checkmark$ \\
(3) & Estimated fixed effect $\hat{\eta}_{i}$ & $\checkmark$ & $\checkmark$ & $\checkmark^{\dagger}$ & $\checkmark^{\dagger}$ & & & & & & \\
(4) & Std. dev. of $\hat{\eta}_{i}$ & $\checkmark$ & $\checkmark$ & & & & & & & \\
(5) & Std. dev. of $\left(w_{i t}-\hat{\eta}_{i}\right)$ & $\checkmark$ & & & & $\checkmark$ & & & & \\
(6) & Unemployment $u_{i t}$ & $\checkmark$ & $\checkmark$ & $\checkmark$ & & & & & & & \\
(7) & Log tenure at current job & $\checkmark$ & $\checkmark$ & $\checkmark$ & & $\checkmark$ & & & & & $\checkmark$ \\
(8) & Job found through friends $f_{i t}$ & $\checkmark$ & $\checkmark$ & $\checkmark$ & & & & & & & $\checkmark$ \\
(9) & Employed when found job & $\checkmark$ & & & & $\checkmark$ & & & & & $\checkmark$ \\
\hline
\end{tabular}

$\dagger$ Coefficients not targeted in estimation.

friends identify the within-worker dispersion of offers $\left\{\sigma_{f}, \sigma_{d}\right\}$.

A regression of unemployment $u_{i t}$ on race, the estimated fixed effect $\hat{\eta}_{i}$, experience, and a constant targets the parameters of the job destruction rate $\left\{\Delta_{\text {race }}, \Delta_{\text {hcap }}, \Delta_{\text {exp }}, \Delta_{0}\right\}$ in Equation 9. A similar regression of $\log$ tenure at the current job on the same regressors targets the arrival rate parameters $\left\{\Lambda_{\text {race }}^{d}, \Lambda_{\text {hcap }}^{d}, \Lambda_{\text {exp }}^{d}, \Lambda_{0}^{d}\right\}$ and $\left\{\Lambda_{\text {race }}^{f}, \Lambda_{\text {hcap }}^{f}, \Lambda_{\text {exp }}^{f}, \Lambda_{0}^{f}, \Lambda_{s}^{f}\right\}$ in Equations 5 and 6 as well as the dependence of job loss on provenance $\Delta_{f}$, and a regression of $f_{i t}$ (an indicator of whether the current job was found through friends) on these regressors distinguishes the arrival rate parameters for direct offers from those for offers through friends.

An indicator that $i$ was employed when the current job was found is averaged for jobs found directly and those through friends to distinguish on-the-job search from search in unemployment for both sources of offers, parameterized by $\Lambda_{\mathrm{emp}}^{d}$ and $\Lambda_{\mathrm{emp}}^{f}$.

The set of targeted statistics also includes averages by race of log wages, unemployment, and the fraction of jobs found through friends. While these are featured in regressions above, the regressions include other variables endogenous to the model, and it is important that the simulation match these crucial aggregate statistics as well.

\subsection{Procedure}

Practically, estimation proceeds as follows. First, a vector of 34 targeted statistics including those indicated by Table 5 is calculated using the actual data. Then, starting values of the parameters are chosen from preliminary regressions. The model is simulated, and a vector of targeted statistics is 
calculated from the simulated outcomes. The difference between the the vector of true statistics and the vector of simulated statistics is weighted by $W$, the inverse covariance matrix of the target statistics (computed separately, from 500 draws of the original data).

$$
\rho\left(v^{\text {true }}, v^{\text {sim }}\right)=\left(v^{\text {true }}-v^{\text {sim }}\right)^{\prime} W\left(v^{\text {true }}-v^{\text {sim }}\right)
$$

An algorithm ${ }^{17}$ searches for the set of parameters which, when simulated, yield a vector of statistics $v^{\text {sim }}$ that minimizes this distance $\rho\left(v^{\text {true }}, v^{\text {sim }}\right)$.

Finally, confidence intervals are constructed by bootstrapping. The set of workers is resampled with replacement to generate a synthetic sample, and the parameters are reestimated using the synthetic sample. The baseline and counterfactual simulations are run using the new parameters and synthetic sample. This is repeated 360 times to generate confidence intervals.

\subsection{Caveats}

This section concludes with some important caveats. There are reasons to suspect this paper's estimate of the role of social capital may be an underestimate. First, if there is racal bias in direct hiring, $\eta_{i}$ will not represent $i$ 's productivity. ${ }^{18}$ This alone does not affect the main results, but if there is more racial bias or discrimination against black workers in direct hiring than in hiring through friends, then the wages of black workers will understate their human capital. In this case, the racial difference in social capital will be larger than estimated.

Second, if there is within-race heterogeneity in social capital that is correlated with human capital, then wages of jobs found through friends may appear to depend on human capital more than they do. This would lead to an underestimate of the effect of increasing social capital. ${ }^{19}$ For these reasons, this paper's results should be seen as conservative. Appendix C examines both cases in further detail.

\footnotetext{
${ }^{17}$ Specifically, MATLAB's fminsearch is used, which employs the Nelder-Mead simplex algorithm.

${ }^{18}$ Bertrand and Mullainathan (2004) find that employers are less likely to respond to applications with names indicating a black applicant and Kline and Walters (2020) develop methods to identify which employers are discriminating, though Neal and Johnson (1996) argue that most of the wage gap between black workers and others is accounted for by differences in skill as measured by the AFQT.

${ }^{19}$ If social capital were negatively correlated with human capital, this paper would overestimate the importance of social capital. However, available evidence generally contradicts this possibility: self-reported sociability is positively correlated with AFQT score and wages, and the network wage premium grows with education.
} 


\section{Results}

\subsection{Parameter estimates}

Table 6 presents the estimates of the parameters related to the distribution of human capital and its growth with work experience. The estimated group difference in mean initial human capital reflects inequality in educational attainment as well as other factors mentioned in Section 3.

Table 6: Human capital parameter estimates

\begin{tabular}{lccc} 
& & Estimate & $95 \%$ CI \\
\hline \hline Mean initial human capital, non-black & $\mu_{\text {non-black }}$ & 4.825 & {$[4.76,4.88]$} \\
Mean initial human capital, black & $\mu_{\text {black }}$ & 4.615 & {$[4.55,4.67]$} \\
Std. dev. initial human capital, non-black & $\sigma_{\text {non-black }}$ & 0.525 & {$[0.513,0.539]$} \\
Std. dev. initial human capital, black & $\sigma_{\text {black }}$ & 0.302 & {$[0.288,0.319]$} \\
Dependence of direct wages on experience & $\alpha_{1}$ & 0.210 & {$[0.206,0.215]$} \\
Dependence of direct wages on experience squared & $\alpha_{2}$ & -1.08 E-3 & {$[-0.0111,-0.0105]$} \\
\hline
\end{tabular}

The other parameters that determine the wage distribution of offers are given in Table 7. Recall that the dependence of offers found directly on human capital is normalized to one (Equation 1), so there are no analogues of $\beta_{\text {hcap }}, \beta_{\text {exp }}$, or $\beta_{0}$ for jobs found directly. The wages of jobs found through friends are higher but have slightly lower variance, and depend less on human capital, perhaps supporting the argument of Datcher Loury (2006) that jobs found through friends can be an important last resort. The racial difference in social capital does seem to affect wage offers, even after controlling for the fact that the wages of jobs found through friends may depend on human capital differently than those of jobs found directly. 
Table 7: Wage offer distribution parameter estimates

\begin{tabular}{lccc} 
& & Estimate & 95\% CI \\
\hline \hline $\begin{array}{l}\text { Wage premium, jobs found through } \\
\text { friends }\end{array}$ & $\beta_{0}$ & 0.470 & {$[0.458,0.483]$} \\
$\begin{array}{l}\text { Dependence on initial human capital } \eta_{i}, \\
\text { jobs found through friends }\end{array}$ & $\beta_{\text {hcap }}$ & 0.943 & {$[0.931,0.965]$} \\
$\begin{array}{l}\text { Dep. on acquired human capital } h_{i t}, \text { jobs } \\
\text { found through friends }\end{array}$ & $\beta_{\exp }$ & 0.916 & {$[0.873,0.941]$} \\
$\begin{array}{l}\text { Dep. on racial difference in social capital } \\
s_{r(i)}, \text { jobs found through friends }\end{array}$ & $\beta_{s}$ & -0.088 & {$[-0.090,-0.086]$} \\
$\begin{array}{l}\text { Standard deviation of shocks, direct } \\
\text { offers }\end{array}$ & $\sigma_{d}$ & 0.442 & {$[0.427,0.455]$} \\
$\begin{array}{l}\text { Standard deviation of shocks, offers } \\
\text { found through friends }\end{array}$ & $\sigma_{f}$ & 0.467 & {$[0.455,0.481]$} \\
\hline
\end{tabular}

Table 8 presents the offer receipt parameter estimates. At a given level of human capital, black workers receive fewer offers directly, but about the same through friends, as non-black workers. This is perhaps unexpected given Table 1, but consistent with Wolpin (1992). 
Table 8: Offer receipt parameter estimates

\begin{tabular}{|c|c|c|c|}
\hline & & Estimate & $95 \% \mathrm{CI}$ \\
\hline $\begin{array}{l}\text { Constant, offers received directly } \\
\text { in employment }\end{array}$ & $\Lambda_{0}^{d}$ & -0.875 & {$[-0.904,-0.839]$} \\
\hline $\begin{array}{l}\text { Constant, offers through friends in } \\
\text { employment }\end{array}$ & $\Lambda_{0}^{f}$ & -2.803 & {$[-2.882,-2.727]$} \\
\hline Difference for black workers & $\Lambda_{\text {race }}^{d}$ & -0.0151 & {$[-0.0155,-0.0148]$} \\
\hline $\begin{array}{l}\text { Dependence of arrival rate on } \\
\text { racial difference in social capital }\end{array}$ & $\Lambda_{s}$ & 0.0122 & {$[0.0119,0.0126]$} \\
\hline $\begin{array}{l}\text { Dependence on initial human } \\
\text { capital } \eta_{i} \text {, jobs found directly }\end{array}$ & $\Lambda_{\text {hcap }}^{d}$ & 0.0285 & {$[0.0278,0.0294]$} \\
\hline $\begin{array}{l}\text { Dependence on initial human } \\
\text { capital } \eta_{i} \text {, jobs found through } \\
\text { friends }\end{array}$ & $\Lambda_{\text {hcap }}^{f}$ & 0.0086 & {$[0.0084,0.0088]$} \\
\hline $\begin{array}{l}\text { Dependence on acquired human } \\
\text { capital } h_{i t} \text {, jobs found directly }\end{array}$ & $\Lambda_{\mathrm{exp}}^{d}$ & 0.0175 & {$[0.0171,0.0180]$} \\
\hline $\begin{array}{l}\text { Dependence on acquired human } \\
\text { capital } h_{i t} \text {, jobs found through } \\
\text { friends }\end{array}$ & $\Lambda_{\exp }^{f}$ & 0.0050 & {$[0.0049,0.0051]$} \\
\hline $\begin{array}{l}\text { Diff. when unemployed, jobs } \\
\text { found directly }\end{array}$ & $\Lambda_{\mathrm{emp}}^{d}$ & 0.662 & {$[0.644,0.691]$} \\
\hline $\begin{array}{l}\text { Difference when unemployed, jobs } \\
\text { found through friends }\end{array}$ & $\Lambda_{\mathrm{emp}}^{f}$ & 0.883 & {$[0.858,0.923]$} \\
\hline
\end{tabular}

Table 9 gives the estimates of the job destruction parameters. Human capital lowers the rate of job destruction, and black workers are more likely to lose their jobs. Jobs found through friends are slightly less likely to be lost, as found in previous papers, though here the difference is not large. 
Table 9: Job destruction parameter estimates

\begin{tabular}{lccc} 
& & Estimate & $95 \%$ CI \\
\hline \hline Constant & $\Delta_{0}$ & -2.44 & {$[-2.51,-2.38]$} \\
Difference for black workers & $\Delta_{\text {race }}$ & 0.276 & {$[0.268,0.283]$} \\
Dependence on initial human capital $\eta_{i}$ & $\Delta_{\text {hcap }}$ & -0.599 & {$[-0.614,-0.587]$} \\
Dependence on acquired human capital $h_{i t}$ & $\Delta_{\text {exp }}$ & -0.0039 & {$[-0.0040,-0.0038]$} \\
Dependence on how job was found $f_{i t}$ & $\Delta_{\mathrm{f}}$ & -0.073 & {$[-0.074,-0.070]$} \\
\hline
\end{tabular}

\subsection{Simulated statistics}

With the parameters estimated, it is possible to simulate the model in both baseline and counterfactual scenarios. Table 10 presents the values of some key moments of interest for both simulated and actual data, as well as a counterfactual in which there is no racial difference in social capital (i.e., $s_{i}$ is set to zero for all workers). Estimates of the full list of 34 targeted moments and regression coefficients from Table 5 are in Table 13 in Appendix A. The model predictions of the frequency with which accepted job offers are found through friends are close to the data, while simulated unemployment and earnings are higher than they are in the data (though the perceived difference in the latter is perhaps exaggerated by reporting these figures in dollars rather than log dollars, which is how they are treated in the model and estimation). 
Table 10: Key moments

\begin{tabular}{llccc|c} 
& & Data & Simulated & Counterfactual & Difference \\
\hline \hline & Non-black & 23.7 & 24.2 & - & - \\
$\begin{array}{l}\text { \% jobs found } \\
\text { through friends }\end{array}$ & Black & 26.2 & 23.3 & 23.1 & - \\
& & & {$[20.2,25.3]$} & {$[20.0,25.1]$} & {$[-0.68,0.30]$} \\
\hline & Non-black & 442 & 511 & - & - \\
$\begin{array}{l}\text { Weekly earnings } \\
\text { of employed }\end{array}$ & & & {$[489,529]$} & - & - \\
$(2016$ \$) & Black & 381 & 421 & 429 & 7.82 \\
& & & {$[407,439]$} & {$[414,447]$} & {$[6.38,9.24]$} \\
\hline & Non-black & 6.15 & 8.19 & - & - \\
$\begin{array}{l}\text { Unemployment } \\
\text { rate, \% }\end{array}$ & & & {$[7.36,9.04]$} & - & - \\
& Black & 8.95 & 11.9 & 12.0 & 0.10 \\
& & & {$[10.6,12.8]$} & {$[10.6,12.9]$} & {$[-0.04,0.22]$} \\
\hline
\end{tabular}

Note: The counterfactual sets the social capital of black workers equal to that of non-black workers; since this doesn't affect non-black workers, their outcomes are unchanged and thus marked with a dash. Bootstrapped 95\% confidence intervals are given in brackets. The rightmost column gives the difference between the counterfactual simulation and the baseline simulation.

The counterfactual exercise is similar to that undertaken in Table 4. Specifically, the racial difference in social capital is set to zero to determine how much of the wage and unemployment gaps it can account for. The main finding agrees with that of Table 4: racial differences in jobs found through friends can account for $9.6 \%$ of the simulated racial gap in earnings of employed workers $(95 \%$ confidence interval: $[7.6 \%, 12.0 \%])$. The simulated racial unemployment gap is essentially unchanged. Overall, the model results conform closely with the reduced-form estimates of Section 2, suggesting that social connections affect labor market inequality primarily through differences in the wages of jobs found through friends.

\section{Social capital investment}

\subsection{Background}

If having the right friends is so valuable on the labor market, then people may have an incentive to choose their friends carefully. Should we then expect segregation in social networks and the labor market inequality it causes to eventually fade away, or can these phenomena persist in equilibrium? That is, will people eventually reduce inequality by choosing different friends, or might it remain, 
absent policy intervention?

This section sketches a theoretical model to demonstrate that social networks can remain segregated in equilibrium, ${ }^{20}$ even when connections are chosen by workers. Its key qualitative features match the stylized facts established earlier in the paper: social network segregation, inequality in education and labor market outcomes, and inequality in the labor market benefits of social connections at a fixed level of human capital. This model is a simplification of the job search model used in the rest of the paper, rather than a microfoundation. It is in the spirit of the network job search model of Calvó-Armengol and Jackson (2004) but with finite periods, and expanded to include endogenous network formation and human capital investment. The purpose of this section is to provide a plausible intuitive explanation for the aggregate phenomena listed above, but I am aware of no data set including the micro-data on social connections, educational attainment, and labor market outcomes (including which jobs were found through friends) that would permit estimation of this model. Accordingly, the model is kept as sparse as possible to showcase the mechanism clearly.

The intuition is as follows. People choose (in equilibrium) friends who belong to their group, since they expect to end up doing similar types of work, and those friends will be most helpful in finding jobs. Within a group, people pursue similar levels of human capital investment, since the costs of doing otherwise can be prohibitive given the importance of having similarly situated friends in the labor market. Finally, members of a group end up with similar labor market outcomes, fulfilling the expectations that prompted social network segregation to begin with.

These results rely crucially on individuals' ability to choose friends based on their attributes, and thus differ qualitatively from work that does not share this feature. In particular, Ioannides (2019) adapts the Cabrales, Calvó-Armengol, and Zenou (2011) model of network formation and productive effort to an intergenerational setting, and shows that allowing each player to choose a one-dimensional level of socialization reduces inequality in production. By contrast, I show that if people are allowed to choose whom they socialize with, rather than simply a general level of socialization as in Cabrales, Calvó-Armengol, and Zenou (2011), inequality can in fact become entrenched. This accords with network formation models such as those of Badev (2019), LewisFaupel (2016), Agostinelli (2018), and Mele (2020), in which the ability of people to choose peers based on their attributes is important for correctly accounting for the equilibrium effects of policy. But rather than simply including utility benefits for making friends with certain attributes, this section's model complements previous work by featuring a concrete reason (labor market benefits) for favoring certain types of friends.

The main results of this section (Proposition 1) are essentially two groups playing different strategies in the same game, and one is failing to coordinate to achieve a superior outcome. Social

\footnotetext{
${ }^{20}$ Partial equilibrium—-this section does not model firm behavior
} 
network segregation and inequality in human capital and wage outcomes can occur in equilibrium here without taste-based bias (on the part of firms or in friendship formation) or differences in the cost of human capital investment. This is not, of course, to deny that such forces may be important factors in existing inequality, but to demonstrate that inequality could persist even if these forces were removed.

\subsection{A simple model with endogenous connections}

Consider a population of $N$ expected-utility-maximizing people, of which $N_{r}$ belong to group $r$ for $r \in\{0,1\}$, and assume that both group sizes are even. ${ }^{21}$ In this section the groups need not be racial categories as defined earlier - the results apply more generally. Each player $i$ is endowed with a personal cost of human capital investment $c_{i}$, which is equal to zero for a fraction $\theta_{r}$ of group- $r$ members (call these "high types") and equal to $\bar{c} \in\{0,1\}$ for the rest ("low types"). This cost could represent differences in local schools, the availability of family money for tutors, or any other impediments to acquiring human capital. $\theta_{0}$ and $\theta_{1}$ are common knowledge.

The timing is as follows.

1. Each person $i$ chooses $\gamma_{i r} \in\{0,1\}$ for each $r \in\{0,1\}$, denoting whether $i$ seeks connections with people from group $r$. Simultaneously, each person $i$ also makes a human capital decision $\hat{\eta}_{i} \in\{0,1\}$, incurring cost $c_{i}$ if $\hat{\eta}_{i}=1$.

2. Each person is randomly connected with another such that $\gamma_{i r(j)}=\gamma_{j r(i)}=1$, if such a person exists (but nobody gets more than one connection). ${ }^{22}$

3. Each person $i$ receives $o_{i}$ offers, where $o_{i}$ follows a Poisson distribution with parameter $\xi$. Each offer is for a job that pays $\hat{\eta}_{i}$. If $i$ receives at least one offer, $i$ accepts the offer and receives $\hat{w}_{i}=\hat{\eta}_{i}$.

4. If $i$ received no offers $\left(o_{i}=0\right)$ but $i$ has a connection $j$ who received more than one offer $\left(o_{j}>1\right)$ and $i$ is at least as qualified as $j\left(\hat{\eta}_{i} \geqslant \hat{\eta}_{j}\right)$, then $j$ 's extra offer is passed to $i$ and $i$ receives $\hat{w}_{i}=\hat{\eta}_{j}$ (if so, $\hat{f}_{i}=1$ ).

5. A player $i$ with no offers in the previous two steps receives $\hat{w}_{i}=-1$. Utility $\hat{U}_{i}$ is realized for all players.

\footnotetext{
${ }^{21}$ This ensures that in equilibrium, nobody will be left unpaired.

${ }^{22}$ This allocation of connections can be accomplished by randomly ordering the players and then, in order, randomly assigning to each a connection that has not been assigned yet from the set of players such that $\gamma_{i r(j)}=\gamma_{j r(i)}=1$. If no available connections remain, move to the next without assigning a connection (though in equilibrium this is not a worry—see Lemma 1).
} 
Utility $\hat{U}_{i}$ consists of wages $\hat{w}_{i}$ less the cost of human capital investment. ${ }^{23}$

$$
\hat{U}_{i}=-c_{i} \hat{\eta}_{i}+\hat{w}_{i}
$$

In this section's model workers receive direct offers that match their human capital investment, and pass them along to qualified friends (those with equal or greater human capital) if more than one offer is received. Note that if $i$ invested in human capital $\left(\hat{\eta}_{i}=1\right)$ and $i$ 's only offer comes through a player $j$ with less human capital $\left(\hat{\eta}_{j}<\hat{\eta}_{i}\right)$, $i$ 's wage will be only be $\hat{\eta}_{j}$-less than $i$ 's own human capital. A worker $i$ cannot receive an offer from a connection $j$ who has greater human capital than $i$. The idea is that workers search for jobs that will reward their human capital investment, but may be able to take lower-paying jobs if the initial search is unsuccessful. It is important for the results of the model that workers cannot receive offers for jobs that require more human capital than they have, ${ }^{24}$ though workers are able to receive offers for jobs that require less human capital. ${ }^{25}$ Unlike the model presented in Section 3, the labor market in this section is mechanical and requires no choices on the part of the worker. ${ }^{26}$

A connection in this model is a potential source of job offers later in life, but this need not be $i$ 's best friend-a long literature (e.g. Granovetter, 1973) emphasizes that helpful referrals often come through weak ties, as members of close-knit groups of friends are likely to be competing for the same offers. For simplicity it is assumed that each player has at most one connection. ${ }^{27}$ Like other models of network effects, this one requires mutual interest $\left(\gamma_{i r(j)}=\gamma_{j r(i)}=1\right)$ from two people for a connection to be made. ${ }^{28}$

Players are permitted to condition on the group $r(j)$ of others when choosing to seek social

\footnotetext{
${ }^{23}$ The notation in this section is chosen to suggest connections to the notation used in the rest of the paper. In this section human capital $\hat{\eta}_{i}$ only takes on two values, which can be thought of as a simplification that can account for some of the group-level differences in the continuous initial human capital variable $\eta_{i}$ of the main model of Section 3 . Similar to before, $\hat{f}_{i}$ is an indicator that $i$ 's job was found through friends. In this section wages are simplified to $\hat{w}_{i}$. Note that here there are three possible wages: $-1,0$, and 1.

${ }^{24}$ While firm behavior is not modeled explicitly, this suggests that firms have specific tasks in mind for which underqualified workers would not be productive, and thus not worth hiring. Some workers end up not finding work that reflects their human capital, or not finding work at all-frictions in the labor market.

${ }^{25}$ The main qualitative results (Proposition 1) would hold even if this were not the case.

${ }^{26}$ There is only one period of work here and lower-paying offers come only after higher-paying offers, so there's no reason for a worker not to take the first offer.

${ }^{27}$ Permitting more connections requires more complicated protocols resolving whom to pass offers to, but is not necessary to demonstrate the main qualitative results. Restricting the number of connections to one per person does prohibit some interesting network results, such as the finding of Calvó-Armengol and Jackson (2004) that the labor market outcomes of indirectly linked players are negatively correlated in the short term (as they compete for job offers from mutual friends) but positively correlated in the long run.

${ }^{28}$ Examples of other network formation papers that require mutual interest for links to form include Agostinelli (2018) in the proximate context of childhood skill investment, the social collateral literature surveyed in Ambrus, Mobius, and Szeidl (2014), and the literature on relational goods and voting surveyed by Uhlaner (2018).
} 
connections but cannot condition on type. If, however, the proportion of high types $\theta_{r}$ varies by group $r$, group may be used by players as a proxy for type. Notably, there is no built-in homophily in this model (as in Montgomery, 1992)_players have no preference for friends of their own group. In reality of course this may not the case; this assumption is made to demonstrate that even without in-group preferences, segregated social networks can result from people seeking connections with similar human capital and labor market expectations.

In this parsimonious model, social connections do not depend directly on one's human capital decision. This may seem unnatural for some friendships; after all, friends are often made in school. In this model, the wage conditional on finding a job in step 3 can be thought of as incorporating any job market benefits of human capital investment, including jobs found through friends made in school that were not made earlier. All the results require is that some potentially useful social connections are made before human capital investment.

Assume that the cost of human capital is low enough that low types will invest in human capital if their (potential) social connections are investing as well, but high enough that at least group-0 members will not invest without peers' investment. In terms of parameters,

$$
1-e^{-\xi}+2 \theta_{0} e^{-\xi}\left(1-(1+\xi) e^{-\xi}\right)<\bar{c}<1-e^{-\xi}+2 e^{-\xi}\left(1-(1+\xi) e^{-\xi}\right) .
$$

Since the expected number of offers $\xi$ is a positive real number and the group-0 proportion of low types $\theta_{0}$ is in the interval $(0,1)$, there always exists a cost $\bar{c}$ that satisfies Equation 14.

\subsection{Equilibrium}

A strategy for $i$ entails, for each possible value of $c_{i} \in\{0, \bar{c}\}$ (corresponding to $i$ 's type), $i$ 's choice

of whether to try to connect with each group $\left\{\gamma_{i r}\right\}_{r \in\{0,1\}}$, and a human capital investment choice $\hat{\eta}_{i} \in\{0,1\}$.

For simplicity, restrict attention to strategy profiles in which all players of a given group $r$ play the same strategy, and call these "symmetric strategy profiles." These are sufficient to provide an explanation for the observed aggregate phenomena. Equilibrium refers to standard Nash equilibrium: a strategy profile such that given the strategies of others, no player has a profitable deviation (even among actions that differ from other members of that player's group).

Given that $i$ has a connection $j$ and a vector of human capital choices $\hat{\eta}$, the chance that $i$ receives an offer equal to $\hat{\eta}_{i}$ is

$$
\begin{aligned}
\operatorname{Pr}\left(\hat{w}_{i}=\hat{\eta}_{i}\right) & =\operatorname{Pr}\left(o_{i}>0\right)+\operatorname{Pr}\left(o_{i}=0\right) \operatorname{Pr}\left(o_{j}>1\right) \operatorname{Pr}\left(\hat{\eta}_{j}=\hat{\eta}_{i}\right) \\
& =\left(1-e^{-\xi}\right)+e^{-\xi}\left(1-(1+\xi) e^{-\xi}\right) \operatorname{Pr}\left(\hat{\eta}_{j}=\hat{\eta}_{i}\right)
\end{aligned}
$$


The chance of receiving at least one direct offer in step 3 is $1-e^{-\xi}$. With complementary probability $e^{-\xi}, i$ receives no direct offer but can still receive an offer of wage $\hat{\eta}_{i}$ if $i$ 's connection $j$ receives more than one offer (chance $\left(1-(1+\xi) e^{-\xi}\right)$ ) and has the same human capital level as $i$.

If $i$ invests in human capital $\left(\hat{\eta}_{i}=1\right)$, it is possible that $i$ receives no offer directly but receives an inferior offer $\hat{w}_{i}=0$ through connection $j$. The chance this happens is

$$
\begin{aligned}
\operatorname{Pr}\left(\hat{w}_{i}=0 \mid \hat{\eta}_{i}=1\right) & =\operatorname{Pr}\left(o_{i}=0\right) \operatorname{Pr}\left(o_{j}>1\right) \operatorname{Pr}\left(\hat{\eta}_{j}=0\right) \\
& =e^{-\xi}\left(1-(1+\xi) e^{-\xi}\right) \operatorname{Pr}\left(\hat{\eta}_{j}=0\right)
\end{aligned}
$$

This happens if $i$ receives no direct offer (chance $e^{-\xi}$ ), $j$ receives multiple offers (chance $1-$ $\left.(1+\xi) e^{-\xi}\right)$, and $j$ has human capital level 0 .

If neither of the above occurs, $i$ receives $\hat{w}_{i}=-1$.

Lemma 1. Given a symmetric strategy profile for players other than $i$ (one in which all players of a given group who are not $i$ play the same strategy), there exists a best response for $i$ that includes $\hat{\gamma}_{i r(j)}=0$ for all $j$ such that $\hat{\gamma}_{j r(i)}=0$.

Lemma 1 says that there is no benefit to seeking connections from those who are not seeking connections with you (proofs are deferred to Appendix D). In equilibrium, efforts at connection are reciprocated (or there exists a payoff-equivalent equilibrium in which they are). ${ }^{29}$

Lemma 2. High types always invest in human capital in equilibrium: $c_{i}=0 \Longrightarrow \hat{\eta}_{i}=1$.

\subsubsection{Segregated equilibrium}

The main result of this section is that an equilibrium exists featuring the main stylized facts emphasized in Section 2: social network segregation and inequality in human capital and wages.

Proposition 1. If Equation 14 holds, there exists an equilibrium in pure, symmetric strategies in which:

i. $\gamma_{i r}=1 \Longleftrightarrow r=r(i)$ (social network segregation)

ii. $E\left(\hat{\eta}_{i} \mid r(i)=1\right)>E\left(\hat{\eta}_{j} \mid r(j)=0\right)$ (group education gap)

iii. $E\left(\hat{w}_{i} \mid r(i)=1\right)>E\left(\hat{w}_{j} \mid r(j)=0\right)$ (group wage gap)

iv. $E\left(\hat{w}_{i} \mid r(i)=1, \hat{\eta}_{i}=\eta, f_{i}=1\right)>E\left(\hat{w}_{j} \mid r(j)=0, \hat{\eta}_{j}=\eta, f_{j}=1\right)$ (group wage gap for jobs found through friends, conditional on human capital)

\footnotetext{
${ }^{29} \mathrm{~A}$ more complicated model might include costs (or opportunity costs) of investment in connections, as in Clark and Tenev (2019), which would prevent players from seeking unreciprocated connections in equilibrium.
} 
Furthermore, (i.) and (ii.) together imply (iii.) and (iv.) for any equilibrium in pure, symmetric strategies.

This segregated, unequal equilibrium exists even if there are no racial differences in the average cost of human capital investment or direct job finding parameters $\xi^{30}$ This is not to imply, of course, that there are no other factors underlying racial inequality in formal educational attainment and labor market outcomes — far from it — but to highlight the power of expectations and social networks even if other factors were removed.

This is not the only equilibrium — of note, there may also exist an equilibrium with higher aggregate welfare in which all players seek social connections with all other players, everyone invests in human capital, and there is no group inequality in wages. ${ }^{31}$ However, this unequal equilibrium is less robust to some reasonable alterations to the model. First, a more realistic model might include some people for whom the cost of human capital is prohibitive even if their peers are investing. If group 0 contains enough such people, the equilibrium without inequality in wages and human capital may not exist. Second, labor market discrimination against group 0 might, as mentioned above, lower the rate of offer arrival $\xi$ for group. This would loosen the constraint on $\bar{c}$, and widening the range of types who would fail to invest in human capital without peers' investment. Third, one can imagine an intergenerational model in which some connections are inherited. In such a model, different initial conditions (group levels of human capital investment) could persist across generations.

The segregated equilibrium exhibits homophily (the tendency of links to form between like individuals) along several dimensions: race, human capital investment, and labor market outcome. In the model group has no inherent significance, but can still function as a coordinating device allowing individuals to sort themselves based on shared expectations for the future. The segregation of social networks is a form of statistical discrimination, as individuals are using what is here a superficial characteristic as a signal of meaningful information about another. The resulting homophily provides another theoretical explanation for the phenomenon, alongside enforcing contribution to public goods (Clark \& Tenev, 2019) and reducing uncertainty in a coordination game (Kets \& Sandroni, 2019).

\section{Conclusion}

This paper is the first to estimate the contribution of social capital inequality to the aggregate wage gap between black workers and others in the US. I find that $10 \%$ of the gap can be explained by

\footnotetext{
${ }^{30}$ In fact, Proposition 1 can hold even if group 1 is more likely to face barriers to human capital investment $\left(\theta_{1}<\theta_{0}\right)$, as long as $\theta_{0}$ satisfies Equation 14.

${ }^{31}$ There also exist two equilibria with network segregation but equal human capital investment.
} 
differences in jobs found through friends - a conservative estimate which may be biased downward by within-group correlation between social capital and human capital (discussed in Section 5.3). Furthermore, such inequality can persist as the coordinated result of segregated social networks and differences in human capital development (Section 7).

The implications of these results may not be immediately obvious. Even if friends are important for finding work, can people be forced to make different friends? Perhaps not directly, but if social connections made early in life persist then neighborhood and school segregation may be especially important in determining labor market outcomes. Furthermore, this paper does have something to say about interventions that do not directly alter social networks. The main result of this paper is that a significant fraction of group inequality in labor market outcomes owes to heterogeneity other than worker human capital that prevents certain workers from finding jobs that reward their skills. Accordingly, alternative hiring practices (for example, affirmative action) may counteract the racial imbalance in job-finding while continuing to provide skilled employees.

More broadly, the results of this paper demonstrate the importance of considering social capital in the study of inequality between groups. While data availability remains an impediment, future work detailing the mechanism by which connections are leveraged on the job market would be very interesting, and key to better understanding the effects of policies in arenas ranging from hiring to housing.

\section{References}

Agostinelli, F. (2018). Investing in Children's Skills: An Equilibrium Analysis of Social Interactions and Parental Investments (Working Paper). University of Pennsylvania.

Aizer, A., \& Currie, J. (2019). Lead and Juvenile Delinquency: New Evidence from Linked Birth, School, and Juvenile Detention Records. Review of Economics and Statistics, 101(4), 575587.

Altonji, J. G., \& Blank, R. M. (1999). Race and Gender in the Labor Market. Handbook of Labor Economics, 3, 3143-3259. https://doi.org/10.1016/S1573-4463(99)30039-0

Ambrus, A., Mobius, M., \& Szeidl, A. (2014). Consumption Risk-Sharing in Social Networks. American Economic Review, 104(1), 149-82.

Arrow, K. J., \& Borzekowski, R. (2004). Limited Network Connections and the Distribution of Wages (FEDS Working Paper No. 2004-41). Board of Governors of the Federal Reserve System.

Badev, A. (2019). Nash Equilibria on (Un)Stable Networks. CoRR, abs/1901.00373arXiv 1901.00373. http://arxiv.org/abs/1901.00373 
Barr, T., Bojilov, R., \& Munasinghe, L. (2019). Referrals and Search Efficiency: Who Learns What and When? Journal of Labor Economics, 37(4), https://doi.org/10.1086/703163, 12671300. https://doi.org/10.1086/703163

Becker, G. S., \& Tomes, N. (1979). An Equilibrium Theory of the Distribution of Income and Intergenerational Mobility. Journal of Political Economy, 87(6), 1153-1189. https://doi. org/10.1086/260831

Bertrand, M., \& Mullainathan, S. (2004). Are Emily and Greg More Employable Than Lakisha and Jamal? A Field Experiment on Labor Market Discrimination. American Economic Review, 94(4), 991-1013. https://doi.org/10.1257/0002828042002561

Brown, M., Setren, E., \& Topa, G. (2015). Do Informal Referrals Lead to Better Matches? Evidence from a Firm's Employee Referral System. Journal of Labor Economics, 34(1), 161209. https://doi.org/10.1086/682338

Burdett, K. (1978). A Theory of Employee Job Search and Quit Rates. The American Economic Review, 68(1), 212-220. http://www.jstor.org/stable/1809701

Bureau of Labor Statistics, US Department of Labor. (2019). National Longitudinal Survey of Youth 1979 cohort, 1979-2000 (rounds 1-19). Center for Human Resource Research (CHRR), The Ohio State University.

Cabrales, A., Calvó-Armengol, A., \& Zenou, Y. (2011). Social Interactions and Spillovers. Games and Economic Behavior, 72(2), 339-360.

Calvó-Armengol, A., \& Jackson, M. O. (2004). The Effects of Social Networks on Employment and Inequality. The American Economic Review, 94(3), 426-454. http://www.jstor.org/ stable/3592937

Carneiro, P., Heckman, J. J., \& Masterov, D. V. (2005). Labor Market Discrimination and Racial Differences in Premarket Factors. The Journal of Law and Economics, 48(1), 1-39.

Clark, A. T., \& Tenev, N. H. (2019). Voting and Social Pressure Under Imperfect Information. International Economic Review, 60, 1705-1735.

Coate, S., \& Loury, G. C. (1993). Will Affirmative-Action Policies Eliminate Negative Stereotypes? The American Economic Review, 83(5), 1220-1240. http://www.jstor.org/stable/ 2117558

Datcher Loury, L. (2006). Some Contacts Are More Equal than Others: Informal Networks, Job Tenure, and Wages. Journal of Labor Economics, 24(2), 299-318. Retrieved August 20, 2017, from http://www.jstor.org/stable/10.1086/499974

Durlauf, S. N. (1996). A Theory of Persistent Income Inequality. Journal of Economic Growth, 1(1), 75-93. https://doi.org/10.1007/BF00163343 
Fang, H., \& Moro, A. (2011). Theories of Statistical Discrimination and Affirmative Action: A Survey (J. Benhabib, M. O. Jackson, \& A. Bisin, Eds.). In J. Benhabib, M. O. Jackson, \& A. Bisin (Eds.), Handbook of Social Economics. Elsevier.

Granovetter, M. S. (1973). The Strength of Weak Ties. American Journal of Sociology, 78(6), 1360-1380. https://doi.org/10.1086/225469

Green, G. P., Tigges, L. M., \& Diaz, D. (1999). Racial and Ethnic Differences in Job-Search Strategies in Atlanta, Boston, and Los Angeles. Social Science Quarterly, 80(2), 263-278. https: //doi.org/10.2307/42863899

Guryan, J., \& Charles, K. K. (2013). Taste-based or Statistical Discrimination: The Economics of Discrimination Returns to its Roots. The Economic Journal, 123(572), F417-F432. https: //doi.org/10.1111/ecoj.12080

Hamilton, D., \& Darity, W. A. (2017). The Political Economy of Education, Financial Literacy, and the Racial Wealth Gap. Federal Reserve Bank of St. Louis Review, 99(1), 59-76.

Holzer, H. J. (1987). Informal Job Search and Black Youth Unemployment. The American Economic Review, 77(3), 446-452. Retrieved June 22, 2014, from http://www.jstor.org/stable/ 1804107

Ioannides, Y. M. (2019). Endogenous Social Networks and Inequality in an Intergenerational Setting (Working paper). Human Capital and Economic Opportunity Global Working Group. Department of Economics, Tufts Univ.

Ioannides, Y. M., \& Datcher Loury, L. (2004). Job Information Networks, Neighborhood Effects, and Inequality. Journal of Economic Literature, 42(4), 1056-1093. https://doi.org/10.1257/ 0022051043004595

Kets, W., \& Sandroni, A. (2019). A Belief-Based Theory of Homophily. Games and Economic Behavior, 115, 410-435.

Kline, P. M., \& Walters, C. R. (2020). Reasonable Doubt: Experimental Detection of Job-Level Employment Discrimination (Working Paper No. 26861). National Bureau of Economic Research. https://doi.org/10.3386/w26861

Lewis-Faupel, S. (2016). The Formation and Human Capital Consequences of High School Social Networks (Working paper). University of Wisconsin-Madison.

Loury, G. C. (1981). Intergenerational Transfers and the Distribution of Earnings. Econometrica, 49(4), 843-867. https://doi.org/10.2307/1912506

McDonald, S. (2011). What's in the "Old Boys" Network? Accessing Social Capital in Gendered and Racialized Networks. Social Networks, 33(4), 317-330.

McDonald, S. (2015). Network Effects Across the Earnings Distribution: Payoffs to Visible and Invisible Job Finding Assistance. Social Science Research, 49, 299-313. 
McHenry, P., \& McInerney, M. (2014). The Importance of Cost of Living and Education in Estimates of the Conditional Wage Gap between Black and White Women. Journal of Human Resources, 49(3), 695-722.

Mele, A. (2020). Does School Desegregation Promote Diverse Interactions? An Equilibrium Model of Segregation Within Schools. American Economic Journal: Economic Policy, 12(2), 228257. https://doi.org/10.1257/pol.20170604

Miller, C. (2017). The Persistent Effect of Temporary Affirmative Action. American Economic Journal: Applied Economics, 9(3), 152-190. https://doi.org/10.1257/app.20160121

Montgomery, J. D. (1991). Social Networks and Labor-Market Outcomes: Toward an Economic Analysis. The American Economic Review, 81(5), 1408-1418. http://www.jstor.org/stable/ 2006929

Montgomery, J. D. (1992). Social Networks and Persistent Inequality in the Labor Market (Working Paper). University of Wisconsin-Madison.

Mouw, T. (2002). Racial Differences in the Effects of Job Contacts: Conflicting Evidence from Cross-Sectional and Longitudinal Data. Social Science Research, 31(4), 511-538. https: //doi.org/10.1016/S0049-089X(02)00020-0

Neal, D. A., \& Johnson, W. R. (1996). The Role of Premarket Factors in Black-White Wage Differences. Journal of Political Economy, 104(5), 869-895. https://doi.org/10.1086/262045

O’Neill, J. (1990). The Role of Human Capital in Earnings Differences Between Black and White Men. The Journal of Economic Perspectives, 4(4), 25-45. http://www.jstor.org/stable/ 1942720

Parks-Yancy, R. (2006). The Effects of Social Group Membership and Social Capital Resources on Careers. Journal of Black Studies, 36(4), 515-545.

Petersen, T., Saporta, I., \& Seidel, M. L. (2000). Offering a Job: Meritocracy and Social Networks. American Journal of Sociology, 106(3), https://doi.org/10.1086/318961, 763-816. https : //doi.org/10.1086/318961

Sacerdote, B. (2011). Peer Effects in Education: How Might They Work, How Big Are They, and How Much Do We Know Thus Far?, In Handbook of the Economics of Education. Elsevier.

Schmutte, I. M. (2015). Job Referral Networks and the Determination of Earnings in Local Labor Markets. Journal of Labor Economics, 33(1), 1-32. https://doi.org/10.1086/677389

Schmutte, I. M. (2016). Labor Markets with Endogenous Job Referral Networks: Theory and Empirical Evidence. Labour Economics, 42, 30-42. https://doi.org/10.1016/j.labeco.2016.06. 005

Simon, C. J., \& Warner, J. T. (1992). Matchmaker, Matchmaker: The Effect of Old Boy Networks on Job Match Quality, Earnings, and Tenure. Journal of Labor Economics, 10(3), 306-330. https://doi.org/10.2307/2535091 
Small, M. L., \& Pager, D. (2020). Sociological perspectives on racial discrimination. Journal of Economic Perspectives, 34(2), 49-67.

Thompson, O. (2018). The Determinants of Racial Differences in Parenting Practices. Journal of Political Economy, 126(1), 438-449.

Uhlaner, C. J. (2018). Social Embeddedness and Rational Turnout. The Oxford Handbook of Public Choice, $1,361$.

Wolpin, K. I. (1992). The Determinants of Black-White Differences in Early Employment Careers: Search, Layoffs, Quits, and Endogenous Wage Growth. Journal of Political Economy, 100(3), 535-560. https://doi.org/10.2307/2138730

\section{A Ancillary tables}

Table 11 shows that the conditional wage premium for jobs found through friends differs across occupations, as does the frequency with which jobs are found through friends. The wage premia are calculated by a fixed effects regression akin to that in Table 2, but also including dummies for the interaction of occupation with whether a job was found through friends.

Table 11: Job market importance of friends by occupation

\begin{tabular}{ccccc}
\hline Occupation & \# obs. & $\begin{array}{c}\text { \% found through } \\
\text { friends }\end{array}$ & $\begin{array}{c}\text { Wage } \\
\text { premium (log } \\
\text { pts) }\end{array}$ & Std. error \\
\hline Professional and Technical & 2,086 & 17.5 & 0.350 & 0.040 \\
Sales & 3,396 & 19.7 & 0.209 & 0.033 \\
Operatives ex. Transport & 892 & 25.9 & 0.201 & 0.056 \\
Clerical and Kindred & 2,055 & 23.8 & 0.201 & 0.038 \\
Craftsmen and Kindred & 1,768 & 26.2 & 0.181 & 0.043 \\
Transport Equipment Operatives & 1,299 & 24.4 & 0.134 & 0.049 \\
Managers and Admin. ex. Farm & 833 & 18.2 & 0.083 & 0.065 \\
Farm Laborers and Foremen & 3,073 & 20.6 & 0.064 & 0.038 \\
\hline
\end{tabular}

Table 12 shows the results of log wages of jobs found directly and jobs found through friends separately regressed on age-adjusted, normalized AFQT score as well as controls for age, age squared, and year. The results for jobs found directly are similar to those of O'Neill (1990) and Neal and Johnson (1996), but the coefficient on race is much larger for jobs found through friends. 
Table 12: Race, AFQT, and jobs found through friends

Regression of log weekly earnings

\begin{tabular}{lcc|cc} 
& \multicolumn{2}{c|}{ Found directly } & \multicolumn{2}{c}{ Found through friends } \\
\hline Variable & Coefficient & Std. Err. & Coefficient & Std. Err. \\
\hline AFQT & 0.1601 & 0.0076 & 0.1479 & 0.0117 \\
AFQT $^{2}$ & 0.0258 & 0.0068 & 0.0018 & 0.0106 \\
Black $_{\text {Age }}$ & -0.0266 & 0.0182 & -0.1155 & 0.0282 \\
Age $^{2}$ & 0.2379 & 0.0179 & 0.3131 & 0.0220 \\
\hline \# obs. & -0.0032 & 2.62 E-4 & -0.0045 & 3.38 E-4 \\
\hline
\end{tabular}

Note: Unreported coefficients include year dummies and a constant. 
Table 13: Targeted statistics, data vs. simulated

\begin{tabular}{|c|c|c|c|c|}
\hline Dependent variable & Indep. var./subset & Data & Simulated & $95 \% \mathrm{CI}$ \\
\hline \multirow[t]{6}{*}{ Log wage $w_{i t}$} & $x_{i t}$ & 0.0430 & 0.1333 & {$[0.1260,0.1417]$} \\
\hline & $x_{i t}^{2}$ & -0.0006 & -0.0039 & {$[-0.0042,-0.0037]$} \\
\hline & $f_{i t}$ & 5.372 & 5.519 & {$[5.431,5.600]$} \\
\hline & $f_{i t} \cdot r_{i}$ & -0.178 & -0.287 & {$[-0.339,-0.241]$} \\
\hline & $f_{i t} \cdot x_{i t}$ & 0.0596 & -0.0079 & {$[-0.0191,0.0032]$} \\
\hline & $f_{i t} \cdot x_{i t}^{2}$ & -0.0023 & 0.0002 & {$[-0.0003,0.0007]$} \\
\hline$w_{i t}$, job through friends & $\hat{\eta}_{i}$ & 0.898 & 0.976 & {$[0.963,0.989]$} \\
\hline \multirow[t]{2}{*}{ Estimated fixed effect $\hat{\eta}_{i}$} & 1 & 5.515 & 5.415 & {$[5.334,5.475]$} \\
\hline & $r_{i}$ & -0.121 & -0.253 & {$[-0.291,-0.217]$} \\
\hline \multirow[t]{2}{*}{ Std. dev. of $\hat{\eta}_{i}$} & Non-black & 0.626 & 0.574 & {$[0.557,0.592]$} \\
\hline & Black & -0.103 & -0.197 & {$[-0.216,-0.177]$} \\
\hline \multirow[t]{2}{*}{ Std. dev. of $\left(w_{i t}-\hat{\eta}_{i}\right)$} & Direct & 0.515 & 0.390 & {$[0.372,0.407]$} \\
\hline & Through friends & 0.504 & 0.366 & {$[0.345,0.389]$} \\
\hline \multirow[t]{4}{*}{ Unemployment $u_{i t}$} & 1 & 0.168 & 0.411 & {$[0.363,0.455]$} \\
\hline & $r_{i}$ & 0.0243 & 0.0200 & {$[0.0076,0.0306]$} \\
\hline & $\hat{\eta}_{i}$ & -0.0128 & -0.0635 & {$[-0.0714,-0.0550]$} \\
\hline & $x_{i t}$ & -0.0051 & 0.0006 & {$[0.0000,0.0014]$} \\
\hline \multirow[t]{5}{*}{ Log tenure at current job } & 1 & 1.180 & 2.299 & {$[2.050,2.524]$} \\
\hline & $r_{i}$ & -0.0710 & -0.1270 & {$[-0.1738,-0.0813]$} \\
\hline & $\hat{\eta}_{i}$ & 0.396 & 0.313 & {$[0.274,0.358]$} \\
\hline & $x_{i t}$ & 0.0865 & 0.0562 & {$[0.0521,0.0602]$} \\
\hline & $f_{i t}$ & 0.0923 & -0.0189 & {$[-0.0636,0.0267]$} \\
\hline \multirow[t]{4}{*}{ Job found through friends $f_{i t}$} & 1 & 0.407 & 0.257 & {$[0.211,0.303]$} \\
\hline & $r_{i}$ & 0.0169 & -0.0109 & {$[-0.0368,0.0053]$} \\
\hline & $\hat{\eta}_{i}$ & -0.0176 & -0.0051 & {$[-0.0121,0.0022]$} \\
\hline & $x_{i t}$ & -0.0062 & 0.0010 & {$[-0.0002,0.0022]$} \\
\hline \multirow[t]{2}{*}{ Employed when found job } & 1 & 0.444 & 0.505 & {$[0.488,0.524]$} \\
\hline & $f_{i t}$ & 0.431 & 0.484 & {$[0.451,0.509]$} \\
\hline
\end{tabular}




\section{B Correcting error in measurement of fixed effects}

Let $\hat{\eta}_{i}$ be the individual fixed effects estimated from Equation 10. Using $\langle\cdot, \cdot\rangle$ to denote covariance, the correct parameter values here are

$$
\beta=\left[\begin{array}{cc}
\langle\eta, \eta\rangle & \langle X, \eta\rangle \\
\langle\eta, X\rangle^{\prime} & \langle X, X\rangle
\end{array}\right]^{-1}\left[\begin{array}{c}
\left\langle\eta, w^{f}\right\rangle \\
\left\langle X, w^{f}\right\rangle^{\prime}
\end{array}\right]
$$

whereas simply running a regression using the estimated fixed effects gives you

$$
\hat{\beta}=\left[\begin{array}{cc}
\langle\hat{\eta}, \hat{\eta}\rangle & \langle X, \hat{\eta}\rangle \\
\langle\hat{\eta}, X\rangle^{\prime} & \langle X, X\rangle
\end{array}\right]^{-1}\left[\begin{array}{c}
\left\langle\hat{\eta}, w^{f}\right\rangle \\
\left\langle X, w^{f}\right\rangle^{\prime}
\end{array}\right] .
$$

Let $o_{i}$ be the number of directly-obtained wage observations recorded for worker $i$. Then the estimated fixed effect is just the true fixed effect plus the average wage shock:

$$
\hat{\eta}_{i}=\eta_{i}+\frac{\sum_{t: f_{i j(t)}=0} \epsilon_{i j(t)}^{d}}{o_{i}} .
$$

Note that the covariance between $\epsilon_{i j(t)}^{d}$ and all right-hand side variables in Equation 11 is zero by assumption, $\operatorname{soc} \operatorname{cov}(\eta, X)=\operatorname{cov}(\hat{\eta}, X)$. And under the assumption that $\left\langle\epsilon_{i j(t)}^{f}, \epsilon_{i j\left(t^{\prime} \neq t\right)}^{d}\right\rangle=0$, $\left\langle\hat{\eta}, w^{f}\right\rangle=\left\langle\eta, w^{f}\right\rangle$. So the only element of Equation 18 that requires correction is $\langle\hat{\eta}, \hat{\eta}\rangle$-we just need to find the true variance of $\eta$.

Taking the variance of Equation 19 yields, assuming i.i.d. $\left\{\epsilon^{d}\right\}$,

$$
\left\langle\hat{\eta}_{i}, \hat{\eta}_{i}\right\rangle=\langle\eta, \eta\rangle+\frac{1}{o_{i}}\left\langle\epsilon^{d}, \epsilon^{d}\right\rangle
$$

Next, observe that $\eta+\epsilon^{d}=\hat{\eta}+\hat{\epsilon}^{d}$, where $\hat{\epsilon}^{d}$ is the estimated residual from Equation 10. So

$$
\begin{gathered}
\left\langle\hat{\epsilon}_{i}^{d}, \hat{\epsilon}_{i}^{d}\right\rangle=\langle\eta, \eta\rangle+\left\langle\epsilon^{d}, \epsilon^{d}\right\rangle+\left\langle\hat{\eta}_{i}, \hat{\eta}_{i}\right\rangle-2\left\langle\epsilon^{d}, \hat{\eta}_{i}\right\rangle-2\left\langle\eta, \hat{\eta}_{i}\right\rangle \\
\left\langle\hat{\epsilon}_{i}^{d}, \hat{\epsilon}_{i}^{d}\right\rangle=\langle\eta, \eta\rangle+\left\langle\epsilon^{d}, \epsilon^{d}\right\rangle+\left\langle\hat{\eta}_{i}, \hat{\eta}_{i}\right\rangle-\frac{1}{o_{i}}\left\langle\epsilon^{d}, \epsilon^{d}\right\rangle-2\langle\eta, \eta\rangle .
\end{gathered}
$$

Combining this with Equation 20 yields an expression for the true variance of $\eta$ in terms of observables

$$
\langle\eta, \eta\rangle=\left\langle\hat{\eta}_{i}, \hat{\eta}_{i}\right\rangle-\frac{1}{o_{i}-1}\left\langle\hat{\epsilon}_{i}^{d}, \hat{\epsilon}_{i}^{d}\right\rangle
$$


Using this in place of $\left\langle\hat{\eta}_{i}, \hat{\eta}_{i}\right\rangle$ in Equation 18 will yield the true parameter estimates $\beta$.

\section{Potential sources of bias}

This section examines potential sources of bias in the estimation of key coefficients. Under the most likely scenarios, this paper underestimates the racial difference in social capital and its effect on wages.

\section{C.1 Within-race correlation between social and human capital}

Suppose that the log wage of a job found through friends is:

$$
w_{i j(t)}^{f}=\beta_{0}+\beta_{\text {hcap }} \eta_{i}+\beta_{\exp }\left(\alpha_{1} x_{i t}+\alpha_{2} x_{i t}^{2}\right)+\beta_{s} s_{i}+\epsilon_{i j(t)}^{f}
$$

This is essentially the same wage equation as Eq. 2, but social capital can now differ by individuals as well as race. Without loss of generality, decompose $i$ 's social capital into an average for $i$ 's race as well as an idiosyncratic component $\xi_{i}$ :

$$
s_{i}=r_{i}+\xi_{i}
$$

Using the orthogonality of $\bar{s}_{r(i)}$ with $\epsilon_{i j(t)}, \xi_{i}$, and the experience terms (and using $\langle\cdot, \cdot\rangle$ to denote covariance), this yields

$$
\beta_{s}=\frac{\left\langle r_{i}, w_{i j(t)}^{f}\right\rangle-\beta_{\mathrm{hcap}}\left\langle\eta_{i}, r_{i}\right\rangle}{\left\langle r_{i}, r_{i}\right\rangle} .
$$

Similarly,

$$
\beta_{\text {hcap }}=\frac{\left\langle\eta_{i}, w_{i j(t)}^{f}\right\rangle-\beta_{s}\left\langle\eta_{i}, r_{i}\right\rangle-\beta_{s}\left\langle\eta_{i}, \xi_{i}\right\rangle}{\left\langle\eta_{i}, \eta_{i}\right\rangle} .
$$

Combining these yields

$$
\beta_{s}=\frac{\left\langle r_{i} w_{i j(t)}^{f}\right\rangle\left\langle\eta_{i}, \eta_{i}\right\rangle-\left\langle\eta_{i}, r_{i}\right\rangle\left\langle\eta_{i}, w_{i j(t)}^{f}\right\rangle}{\left\langle r_{i}, r_{i}\right\rangle\left\langle\eta_{i}, \eta_{i}\right\rangle-\left\langle\eta_{i}, r_{i}\right\rangle^{2}-\left\langle\eta_{i}, r_{i}\right\rangle\left\langle\eta_{i}, \xi_{i}\right\rangle} .
$$

Compare this to the estimate if we simply project $w_{i j(t)}$ on a constant, $r_{i}, \eta_{i}, a_{i t}$, and $a_{i t}^{2}$ : 


$$
\hat{\beta}_{s}=\frac{\left\langle r_{i} w_{i j(t)}^{f}\right\rangle\left\langle\eta_{i}, \eta_{i}\right\rangle-\left\langle\eta_{i}, r_{i}\right\rangle\left\langle\eta_{i}, w_{i j(t)}^{f}\right\rangle}{\left\langle r_{i}, r_{i}\right\rangle\left\langle\eta_{i}, \eta_{i}\right\rangle-\left\langle\eta_{i}, r_{i}\right\rangle^{2}} .
$$

Assume $\left\langle\eta_{i}, r_{i}\right\rangle$ and $\beta_{s}>0$ (this is flipping the race dummy from its interpretation in the rest of the paper, but makes the comparison much easier). If human capital $\eta_{i}$ is correlated with withinrace social capital $\xi_{i}$ as well as race $r_{i}$, then the true value of $\beta_{s}$ will be larger than an estimate which ignores $\xi_{i}$ (and this is assuming we know $\eta_{i}$ ). The intuition is that correlation between $\xi_{i}$ and $\eta_{i}$ inflates the apparent dependence of wages on human capital, resulting in an underestimate of the role of social capital.

\section{C.2 Discrimination in direct hiring}

Now suppose there is discrimination in direct hiring as well as in jobs found through friends, such that

$$
\begin{gathered}
w_{i j(t)}^{d}=\left(\eta_{i}-\kappa^{d} r_{i}\right)+\alpha_{1} x_{i t}+\alpha_{2} x_{i t}^{2}+\epsilon_{i j(t)}^{d} . \\
w_{i j(t)}^{f}=\beta_{\text {hcap }}\left(\eta_{i}-\kappa^{f} r_{i}\right)+\beta_{\exp }\left(\alpha_{1} x_{i t}+\alpha_{2} x_{i t}^{2}\right)+\beta_{0}+\beta_{s} s_{i}+\epsilon_{i j(t)}^{f} .
\end{gathered}
$$

Here black workers wages of jobs found through friends are reduced by $\kappa^{d}$ and those of jobs found through friends are reduced by $\kappa^{f}$. If we estimate individual fixed effects from the direct wage equation, we will be getting an estimate of $\eta_{i}-\kappa^{d} r_{i}$ rather than true human capital $\eta_{i}$. Now, notice that Equation 26 can be rewritten

$$
w_{i j(t)}^{f}=\beta_{\text {hcap }}\left(\eta_{i}-\kappa^{d} r_{i}\right)+\beta_{\exp }\left(\alpha_{1} x_{i t}+\alpha_{2} x_{i t}^{2}\right)+\beta_{0}+\beta_{s} s_{i}+\beta_{\text {hcap }}\left(\kappa^{d}-\kappa^{f}\right) r_{i}+\epsilon_{i j(t)}^{f} .
$$

So if we project $w_{i j(t)}^{f}$ on $\eta_{i}-\kappa^{d} r_{i}$, the experience terms, a constant, and $r_{i}$, instead of $\beta_{s}$ we will get as the estimated coefficient on race

$$
\beta_{s}+\beta_{\text {hcap }}\left(\kappa^{d}-\kappa^{f}\right)
$$

So if $\beta_{s}<0, \beta_{\text {hcap }}>0$, and there is more discrimination in direct hiring than hiring through 
friends $\left(\kappa^{d}>\kappa^{f}\right)$, we will underestimate the magnitude of $\beta_{s}$.

\section{Proofs}

Proof of Lemma 1. Fix a symmetric strategy profile strategies of players other than $i$, including social capital investment $\left\{\gamma_{j r}\right\}_{j \neq i, r \in\{0,1\}}$, and suppose $\gamma_{j r(i)}=0$. Consider a best response for $i$ that includes $\gamma_{i r(j)}=1$. There is no chance $i$ will form a connection with $j$, since $j$ 's group is not reciprocating. $i$ can thus do no worse by switching to $\gamma_{i r(j)}=0$.

Proof of Lemma 2. Investing in human capital does not change the payoff when no offer is received, increases the wages of jobs found directly by 1 , and weakly increases the expected wages of jobs found through connections (jobs found through connections who did not invest in human capital are unchanged, while higher-paying jobs found through connections who did invest in human capital become a possibility). Human capital investment does not change the chance of any of these three (exhaustive) outcomes and it is costless for high types, so it strictly increases a high type's expected payoff.

Proof of Proposition 1. Consider the following strategy profile in pure, symmetric strategies:

- Per (i.), players only seek in-group connections $\left(\gamma_{i r}=1 \Longleftrightarrow r=r(i)\right)$.

- All high types and group-1 low types invest in human capital (choose $\hat{\eta}_{i}=1$ ), while group-0 low types do not.

This strategy profiles entails i. and ii.; we now show that it is an equilibrium.

By Lemma 1, the social connection actions $\left\{\gamma_{i r}\right\}$ proposed above are all best responses. Regardless of a player's human capital choice, seeking out-group connections would result in no higher payoffs, since no out-group connections would be formed without reciprocal interest. And ceasing to seek connections with one's own group would strictly lower one's expected payoff, since for all players in this profile one's connection is a viable possible source of offers when no direct offers are received (Equations 15 and 16). Furthermore, since both group sizes are even everyone has an in-group connection under this strategy profile.

We now show that the human capital investment choices are best responses as well. If $r(i)=1$, then by Equation 15 the chance $i$ 's wage is 1 is $1-e^{-\xi}+e^{-\xi}\left(1-(1+\xi) e^{-\xi}\right)$, since all $i$ 's potential connections have high human capital. With complementary chance $(1-\xi) e^{-2 \xi}, i$ 's wage is -1 (since $\left.\operatorname{Pr}\left(\hat{w}_{i}=0 \mid \hat{\eta}_{i}=1\right)=0\right)$, so

$$
\mathrm{E}\left(\hat{w}_{i} \mid r(i)=1, \hat{\eta}_{i}=1\right)=1-2(1+\xi) e^{-2 \xi}
$$


What expected wage would $i$ get by defecting to $\hat{\eta}_{i}=0$ ? Since any connection would have higher human capital, there would be no chance of a job found through friends. So the expected wage of a group-1 member who defects and does not invest in human capital is

$$
\mathrm{E}\left(\hat{w}_{i} \mid r(i)=1, \hat{\eta}_{i}=0\right)=-e^{-\xi}
$$

By assumption (Equation 14) $\bar{c}<1-e^{-\xi}+2 e^{-\xi}\left(1-(1+\xi) e^{-\xi}\right)$, so all group-1 members prefer to invest in human capital, as specified by the candidate equilibrium.

By Lemma 2, all high types invest in human capital.

If $r(i)=0$ and $i$ is a low type $\left(c_{i}=\bar{c}\right)$, then per the candidate equilibrium $i$ does not invest in human capital: $\hat{\eta}_{i}=0$. So $\operatorname{Pr}\left(\hat{\eta}_{j}=\hat{\eta}_{i}\right)=1-\theta_{0}$ : the fraction of low types in $i$ 's group. Since $i$ does not invest in human capital, $i$ 's highest possible wage is 0 . If $i$ receives no offers (chance $e^{-\xi}$ ) and $i$ 's connection is high type (chance $\theta_{0}$ ) or is a low type (chance $1-\theta_{0}$ ) but gets fewer than 2 offers (chance $(1+\xi) e^{-\xi}$ ), $i$ gets -1 . The expected wage of a group-0 low type is thus

$$
\mathrm{E}\left(\hat{w}_{i} \mid r(i)=0, \hat{\eta}_{i}=0\right)=-e^{-\xi}\left(\theta_{0}+\left(1-\theta_{0}\right)(1+\xi) e^{-\xi}\right)
$$

If $i$ is group- 0 and invests in human capital $\left(\hat{\eta}_{i}=1\right)$, the chance $i$ receives a wage of 1 is $\left(1-e^{-\xi}\right)+\theta_{0} e^{-\xi}\left(1-(1+\xi) e^{-\xi}\right)$, by Equation 15. By Equation 16, the chance that $\hat{w}_{i}=0$ is $\left(1-\theta_{0}\right) e^{-\xi}\left(1-(1+\xi) e^{-\xi}\right)$, which means that the chance that $\hat{w}_{i}=-1$ is the complement, $(1+\xi) e^{-2 \xi}$. The expected wage of a high-type group- 0 member is then:

$$
\mathrm{E}\left(\hat{w}_{i} \mid r(i)=0, \hat{\eta}_{i}=1\right)=1-e^{-\xi}+\theta_{0} e^{-\xi}\left(1-(1+\xi) e^{-\xi}\right)-(1+\xi) e^{-2 \xi}
$$

Comparing Equations 30 and 31 we see that investing in human capital nets a group- 0 member a benefit of $\left(1-e^{-\xi}\right)+2 \theta_{0} e^{-\xi}\left(1-(1+\xi) e^{-\xi}\right)$ (an increase of 1 when a job is found directly, and an increase of 2 when an offer is found through a high type). By assumption (Equation 14), this is less than $\hat{c}$, and low types will not prefer to invest in human capital unless their connections are. So the actions of group-0 low types are best responses. This establishes that no player wishes to deviate to a different level of human capital investment, making the candidate strategy profile an equilibrium that satisfies conditions (i.) and (ii.) of the proposition.

Proof of $i v$. Consider players who invest in human capital. The chance that $i$ 's only offer is received through a connection is $e^{-\xi}\left(1-(1+\xi) e^{-\xi}\right)$, regardless of group. For group-1 members this offer will pay a wage of 1 (left-hand side), but for group- 0 members it pays 1 only if $i$ 's 
connection is high-type (with chance $\left.\theta_{0}\right)$ and 0 otherwise (right-hand side). Since $\theta_{0} \in(0,1)$,

$$
1>1 \times \theta_{0}+0 \times\left(1-\theta_{0}\right) .
$$

Thus

$$
\mathrm{E}\left(\hat{w}_{i} \mid r(i)=1, \hat{\eta}_{i}=1, f_{i}=1\right)>\mathrm{E}\left(\hat{w}_{j} \mid r(j)=0, \hat{\eta}_{j}=1, f_{j}=1\right) .
$$

In this strategy profile everybody in group 1 invests in human capital, so no cross-group comparison is possible for those with $\hat{\eta}_{i}=0$, and this proves (iv.).

Proof of iii. First, consider high types and compare expected wages across groups. Three outcomes are possible for each individual: a job found directly, a job found through a connection, or no offers. There is no group difference in the likelihood of any of these three, and only in jobs found through connections is there a difference in wages. By Equation 33, the wages of jobs found through friends are higher for members of group 1. Therefore, the expected wages of group-1 high types are higher than those of group-0 high types.

Now consider low types and compare expected wages across groups. The chances of receiving an offer directly or through a connection do not differ across groups, but the group-1 low types will receive a wage of 1 in this case while the group- 0 low types will receive at most 0 . If no offer is received, low types in both groups receive -1 . The expected wage of the group-1 low types is thus greater.

Proof that i. and ii. imply iii. and iv. By Lemma 2, high types always invest in human capital in equilibrium. So the only way to have inequality in human capital (ii.) is if group-0 low types do not invest but group-1 low types do. Therefore there is only one equilibrium in pure strategies that satisfies i. and ii., and we have shown above that it entails iii. and iv. 